\title{
A comparison of scopolamine and biperiden as a rodent model for cholinergic cognitive impairment
}

\author{
Inge Klinkenberg • Arjan Blokland
}

Received: 30 June 2010 / Accepted: 9 January 2011 /Published online: 19 February 2011

(C) The Author(s) 2011. This article is published with open access at Springerlink.com

\begin{abstract}
Rationale The nonselective muscarinic antagonist scopolamine hydrobromide (SCOP) is employed as the gold standard for inducing memory impairments in healthy humans and animals. However, its use remains controversial due to the wide spectrum of behavioral effects of this drug. Objective The present study investigated whether biperiden (BIP), a muscarinic $\mathrm{ml}$ receptor antagonist, is to be preferred over SCOP as a pharmacological model for cholinergic memory deficits in rats. This was done by comparing the effects of SCOP and BIP using a battery of operant tasks: fixed ratio (FR5) and progressive ratio (PR10) schedules of reinforcement, an attention paradigm and delayed nonmatching to position task.

Results SCOP induced diffuse behavioral disruption, which included sensorimotor responding (FR5, 0.3 and $1 \mathrm{mg} / \mathrm{kg}$ ), food motivation (PR10, $1 \mathrm{mg} / \mathrm{kg}$ ), attention $(0.3 \mathrm{mg} / \mathrm{kg}$, independent of stimulus duration), and short-term memory (delayed nonmatching to position (DNMTP), 0.1 and $0.3 \mathrm{mg} / \mathrm{kg}$, delay-dependent but also impairment at the zero second delay). BIP induced relatively more selective deficits, as it slowed sensorimotor responding (FR5, $10 \mathrm{mg} / \mathrm{kg}$ ) and disrupted short-term memory (DNMTP, $3 \mathrm{mg} / \mathrm{kg}$, delay-dependent but no impairment at the zero second delay). BIP had no effect on food motivation (PR10) or attention.

Conclusion Muscarinic $\mathrm{m} 1$ antagonists should be considered an interesting alternative for SCOP as a pharmacological model for cholinergic mnemonic deficits in animals.
\end{abstract}

I. Klinkenberg $(\bowtie) \cdot$ A. Blokland

Faculty of Psychology and Neuroscience, Department of

Neuropsychology and Psychopharmacology, European Graduate

School of Neuroscience (EURON), Maastricht University,

PO Box 616, 6200 MD, Maastricht, The Netherlands

e-mail: inge.klinkenberg@maastrichtuniversity.nl
Keywords Sensorimotor $\cdot$ Motivation · Attention

Memory · Animal model · Fixed ratio · Progressive ratio ·

Delayed nonmatching to position $\cdot$ Muscarinic .

Acetylcholine

\section{Introduction}

The muscarinic antagonist scopolamine hydrobromide (SCOP) is used as the gold standard for inducing deficits in human and animal models of memory dysfunction. Justification for this purpose has been provided by the cholinergic hypothesis of geriatric memory dysfunction proposed in the early 1980 s by Bartus et al. (1982). The SCOP model is still used extensively for preclinical testing of new substances designed to treat cognitive impairment (e.g., Barak and Weiner 2009; Buccafusco et al. 2008; Cunha et al. 2008; Loiseau et al. 2008; Vaisman and Pelled 2009). However, its use in cognition research is surrounded by controversy (Hodges et al. 2009; Klinkenberg and Blokland 2010). SCOP is nonselective in terms of binding affinity and, depending on its dose, has the capability to block cholinergic neurotransmission at all muscarinic receptor subtypes m1-m5 (Bolden et al. 1992; Bymaster et al. 2003). As muscarinic receptors are found throughout the brain and body (Caulfield 1993), SCOP is able to induce widespread effects.

Systemic injections of SCOP are capable of disrupting several autonomic nervous system functions. At doses of $0.01 \mathrm{mg} / \mathrm{kg}$ and higher, SCOP can reduce salivation ("dry mouth" side-effect, Dai et al. 1991; Hodges et al. 2009; Shiraishi and Takayanagi 1993), which may lower responding in tasks which employ solid food rewards in order to motivate the animals. Although this problem can be dealt with by using liquid reinforcers (Hodges et al. 2009), the 
majority of studies still favor dry food pellets (Klinkenberg and Blokland 2010). Furthermore, most behavioral tasks also have a strong noncognitive component which can be influenced by SCOP treatment (e.g., increases in locomotor activity, response latency, and omissions at doses lower than $0.03 \mathrm{mg} / \mathrm{kg}$, Bushnell et al. 1997; Klinkenberg and Blokland 2010; Mirza and Stolerman 2000; Phillips et al. 2000; Sipos et al. 1999). Performance on behavioral tasks assessing sensory/stimulus discrimination and/or attentional processes appears to be most susceptible to SCOP treatment (Hodges et al. 2009). Only if doses higher than $0.1 \mathrm{mg} / \mathrm{kg}$ are administered systemically, robust performance deficits on a variety of learning and memory tasks are reported (Klinkenberg and Blokland 2010). Therefore, it has been argued that acetylcholine is predominantly involved in mediating discriminatory and attentional processes (Blokland 1995; Everitt and Robbins 1997; Fibiger 1991; Sarter and Bruno 1997) rather than learning and memory functions (Bartus et al. 1982). In sum, the validity of SCOP as a tool for inducing cognitive dysfunction is questionable.

Of note, systemic administration makes it difficult to dissociate central and peripheral effects. One way to address this issue is to include an experimental group that is given methyl-scopolamine, a quaternary form of SCOP that has the same receptor binding characteristics but supposedly does not cross the blood-brain barrier when given at an equivalent dose (Evans 1975; Harvey et al. 1983; Pradhan and Roth 1968). However, several animal studies have shown that methyl-scopolamine can influence measures of cognitive performance (e.g., Andrews et al. 1994; Herremans et al. 1995; Moore et al. 1992; Pakarinen and Moerschbaecher 1993; van Haaren and van Hest 1989). In addition, methyl-scopolamine cannot control for the widespread blockade of central muscarinic receptors after systemic administration of SCOP (Frey et al. 1985).

Several of the muscarinic receptor subtypes m1-m5 might underlie the cognitive effects of SCOP. Muscarinic $\mathrm{m} 2$ presynaptic autoreceptors have an inhibitory effect on acetylcholine efflux (Bymaster et al. 2003). Hence, m2 antagonists might act as cognitive enhancers by elevating central cholinergic tone, but behavioral data are mixed (Carey et al. 2001; Daniel and Dohanich 2001; Messer and Miller 1988; Quirion et al. 1995). The role of $\mathrm{m} 3$ receptors in cognition is as of yet quite obscure (Bymaster et al. 2003), although one study showed a potential role of $\mathrm{m} 3$ receptors in cognition (Poulin et al. 2010). Information on the involvement of $\mathrm{m} 4$ presynaptic autoreceptors and $\mathrm{m} 5$ postsynaptic in cognitive function is also relatively limited (Wess 2004); there are some indications that the $\mathrm{m} 5$ receptor is implicated in central cerebral blood flow and memory processes (Araya et al. 2006).

Evidence for a role in mnemonic processes in both rodents and humans is strongest for the postsynaptic muscarinic m1 receptor (e.g., Conn et al. 2009; Fornari et al. 2000; Kimura et al. 1999; Kramer-Soares et al. 2006; Roldán et al. 1997; Wezenberg et al. 2005). This receptor is predominantly located in brain regions thought to be important for learning and memory such as cortex and hippocampus; presence of the $\mathrm{m} 1$ receptor in the periphery is relatively limited (Caulfield 1993; Volpicelli and Levey 2004). Hence, $\mathrm{m} 1$ antagonists are considered an interesting option with regards to finding novel pharmacological alternatives to induce cognitive impairment which are not so much hampered by issues of nonselectivity or peripheral side-effects (Conn et al. 2009).

This is the first study to compare the effects of SCOP versus the relatively more selective muscarinic $\mathrm{m} 1$ antagonist biperiden (BIP) (Bolden et al. 1992) on various facets of behavior. Specifically, we wanted to dissociate behavioral effects of these two drugs on a battery of four operant tasks: fixed ratio (FR5) and progressive ratio (PR10) schedules of reinforcement (assessing sensorimotor responding and food motivation, respectively) versus performance in an attention task and a delayed nonmatching to position task (assessing short-term memory). On basis of the direct comparison between both drugs we wanted to determine whether BIP would be preferable over SCOP as a cholinergic memory deficit model.

\section{Methods}

Subjects

All experimental procedures were approved by the local ethical committee for animal experiments at Mastricht University and met governmental guidelines. Twenty male 3-month-old Wistar rats (Harlan, NL) served as subjects in this study. To ensure consistency, the same animals were used in all behavioral tasks. They were housed in pairs in standard type III Makrolon ${ }^{\mathrm{TM}}$ cages on sawdust bedding in an airconditioned room $\left(21^{\circ} \mathrm{C}, 45-55 \%\right.$ humidity $)$ under a reversed light/dark cycle (lights on from 7P.M. to 7 A.M.). Rats were housed in the room in which they were tested. All testing was performed between 12 and 6P.M. Rats had free access to water, but were subjected to a food deprivation regime from Monday through Friday, in order to reduce their weight to about $90 \%$ of their free feeding weight. Food was given ad libitum from Friday afternoon to Sunday afternoon. Food was taken away at Sunday afternoon which caused a sufficient appetite at the morning session on Monday.

\section{Apparatus}

Rats were trained and tested in 10 identical Skinner boxes $(40 \times 30 \times 33 \mathrm{~cm})$. The ceiling of these conditioning cham- 
bers contained a light that illuminated the conditioning chamber during experiments. The left and right sidewalls served as control panels. A recess $(5 \times 5 \mathrm{~cm})$, built into the left side panel $2.5 \mathrm{~cm}$ above the grid floor, contained a food tray with a hinged panel into which a pellet dispenser delivered 45-mg food pellets (Bioserve TestDiet AIN-76A rodent tablets, Frenchtown, NJ, USA). Two retractable stainless steel levers $(4 \mathrm{~cm}$ wide) projected $2 \mathrm{~cm}$ into the conditioning chamber and were located $6 \mathrm{~cm}$ from both sides of the recess, $12 \mathrm{~cm}$ above the grid floor. The conditioning chambers were enclosed in sound-attenuating housing. Background noise was produced by a radio and an exhaust fan. A personal computer controlled the experimental equipment and collected the data.

Fixed ratio (five) task

Rats first underwent five magazine training sessions and were then subjected five times to continuous reinforcement (CRF). Next the rats were trained on a fixed ratio schedule of reinforcement, in which they had to press a lever for five times (FR5) in order to obtain a 45-mg food reward. Reinforcement was continuous; i.e., each set of five lever presses was rewarded. A session was terminated after 60 trials or $30 \mathrm{~min}$, whichever came first. Rats were trained once a day, Monday to Friday, and were given eight FR5 sessions before drug testing started. The measure used to evaluate performance on the FR5 schedule was interresponse time (i.e., time between consecutive lever presses which was averaged for each animal).

Progressive ratio (ten) task

After finishing drug testing in the FR5 task, rats immediately started training on a progressive ratio (PR10) schedule of reinforcement (Hodos 1961). PR tasks are generally used to assess the reinforcing efficacy of a particular type of reward. The rats had to progressively increase the response requirement (steps of ten lever presses) to obtain a food reward. For the first food pellet they were required to press ten times, for the next reinforcement they had to press the lever twenty times, and so on. A session was terminated if a rat did not press the lever for $3 \mathrm{~min}$. Rats were trained once a day, Monday to Friday, and were given eight PR10 sessions before drug testing started. The measure used to evaluate performance in the PR10 task was breakpoint (i.e., number of lever presses made during a session).

\section{Attention task}

After the PR10 task, the rats were subjected to one CRF session before they started training in an attention task. During this task, a light stimulus was presented either on the left side or on the right side of the food reward tray. The duration of the light stimulus varied randomly between 3,1 and $0.3 \mathrm{~s}$. One second after the light stimulus was extinguished, the two levers were inserted simultaneously. When the rat hit the lever on the side of the prior light stimulus (correct response), the rat was rewarded with a food pellet followed by an inter-trial interval of 5-10 s. When the rat hit the lever on the opposite side of the previous light stimulus (incorrect response), the rat was not rewarded and a time-out period of $5 \mathrm{~s}$ was followed by an inter-trial interval (ITI). When the rat did not hit a lever within $3 \mathrm{~s}$ (omission), the rat was not rewarded and both levers were retracted followed by a time-out period of $5 \mathrm{~s}$ and an ITI. A session was terminated after 80 trials or $40 \mathrm{~min}$, whichever came first. A more detailed description of this task is provided by Hoff et al. (2007). Rats were trained once a day, Monday to Friday. The derived behavioral measures were percentage correct, percentage omissions, response time (averaged over all stimulus durations) and two signal detection theory derived measures:

1. The sensitivity index (SI): a signal detection measure for discriminability which was calculated as follows: $\mathrm{SI}=(h-f) /(2(h+f)-(h+f) 2)$, where $h=($ correct left $) /($ correct left + incorrect right) and $f=$ (incorrect left)/ (incorrect left + correct right). A value of zero reflects no discrimination whereas a value of 1 reflects perfect discrimination.

2. Index $Y$ : a signal detection derived variable for evaluating a response bias. This parameter is calculated as follows: (percentage correct left - percentage correct right)/ (percentage correct left + percentage correct right).

A more detailed description of SI, index $Y$, and other signal detection measures can be found elsewhere (Steckler 2001).

Delayed nonmatching to position

After the rats had finished drug testing on the attention task, they immediately started training in a nonmatching to position task, to which subsequently delays were added. This paradigm consisted of two stages: a sample and a choice phase. In the sample phase, one of the two levers was inserted into the operant chamber. After the rat had pressed the sample lever, it was retracted and the rat was required to poke its nose against the hinged panel which gave access to the pellet magazine (positioned equidistantly between the two levers). This was done in order to prevent the rats from using a behavioral strategy (i.e., mediating behavior, Herremans and Hijzen 1997) to perform the delayed nonmatching to position (DNMTP) task (e.g., after pressing a lever they can move to the other side and wait 
for the lever to come out). More than one panel press or keeping the nose in the food tray was without consequence.

After the rat had pushed the panel at least once and had pulled its nose out of the food hopper, both levers were inserted (the choice phase) and the rat was required to press the lever opposite to the one in the sample phase. It was physically not possible for an animal to keep its nose in the pellet magazine and press the levers, as the food hopper and response levers were placed too far apart. A nonmatching lever-press was continuously reinforced with a food reward. There was a 5-s time-out period (and no food reward) when the lever pressed in the "choice" phase was the same one as in the "sample" phase (i.e., when the response was incorrect). The ITI was always $8 \mathrm{~s}$ (also in subsequent testing in the DNMPT task). A session was terminated after 80 trials or $60 \mathrm{~min}$, whichever came first. No limited hold period was used for the sample or choice phase, which means that no omission errors were recorded. A more elaborate description of the nonmatching to position (NMTP) training can be found elsewhere (Blokland et al. 2004; Prickaerts et al. 1999).

Rats were trained once a day, Monday to Friday and received five NMTP training sessions and one forced choice NMTP session (in which the task was continued only after a correct response was given) before delay intervals were being introduced in between the sample and choice phase. The duration of the delays was gradually increased over successive training sessions over a period of about 2.5 weeks. In order to speed up DNMTP training rats now received two daily sessions. The delay interval was randomly chosen from the following five alternatives: 0,2 , 4,8 , or $16 \mathrm{~s}$. The animals were able to keep their nose in the food hopper during the delays or press the food panel repeatedly without any consequence, but could not press the levers as these were retracted during the delay. In previous studies, we have not observed the animals developing a mediating strategy while performing the DNMTP task (e.g., Blokland et al. 2004), as they were required to press the panel of the food well before the choice phase was presented. The measures used to evaluate performance in the DNMTP were percentage correct, response time (averaged over all delays), SI and index $Y$ (see "Attention task" for more information on these last two parameters).

\section{Drug treatment}

Dose range and pretreatment time were chosen based on previous SCOP and BIP data (e.g., Hodges et al. 2009; Jones and Shannon 2000). Dose conditions were determined according to their position on a logarithmic scale. For example, BIP doses were 1,3 , and $10 \mathrm{mg} / \mathrm{kg}$. When converted to logarithms, these values are approximately equally spaced: $0.0,0.5$, and 1.0 , respectively. Doses were titrated on basis of behavioral effects found in our essay. Scopolamine hydrobromide trihydrate $99 \%$ (hereafter abbreviated as SCOP, obtained from Acros Organics) was dissolved in isotonic saline in doses $0,0.1,0.3$, and $1 \mathrm{mg} /$ $\mathrm{kg}$ (milligrams salt per kilogram of body weight), whereas biperiden lactate (hereafter abbreviated as BIP, Akineton ${ }^{\circledR}$ obtained from Laboratorio Farmaceutico S.I.T.) was dissolved in Milli-Q purified water in doses $0,1,3$, and $10 \mathrm{mg} / \mathrm{kg}$ (milligrams salt per kilogram of body weight). We used quite high doses of SCOP and BIP (1 and $10 \mathrm{mg} /$ $\mathrm{kg}$, respectively) as an upper limit at which - certainly in case of SCOP - serious behavioral side-effects were expected. All drug solutions were prepared freshly each day prior to testing. SCOP and BIP were both injected in a volume of $2 \mathrm{ml} / \mathrm{kg}$ (IP) with a pretreatment time of $30 \mathrm{~min}$. Each drug dose was tested once per rat per test. On each testing day, only one SCOP and one BIP dose was given, with half of the rats receiving SCOP and the other half receiving BIP. The order of doses was semi-randomized over testing days.

\section{Repeated testing}

Repeated testing of drugs in the same group of animals offers several advantages over between-group studies (e.g., better statistical power). However, this particular type of design can be associated with tolerance, drug sensitivity and carry-over effects. To ensure sufficient wash-out of the drug, testing days were always separated by at least one drug-free day on which the animals received FR5, PR10, attention task or DNMTP training. Frequency of administration and dose level were kept as low as possible (i.e., no higher doses were tested than those yielding a significant behavioral effect). This procedure minimized the number of injections each rat received. In order to further minimize group differences due to receptor changes, the drug that was given (SCOP or BIP) alternated between groups for the different behavioral tasks; i.e., ten rats received only SCOP doses and the other ten only received BIP doses during testing of one paradigm. When testing of the next behavioral test started this order was reversed: rats which had previously received SCOP, now received BIP and vice versa.

\section{Statistical analysis}

Data were analyzed by parametric analysis of variance (mixed model analysis of variance (ANOVA); SPSS 15.0) with dose as within-subject variable and drug as betweensubject variable. In case an interaction with drug and/or a main effect of drug was found, a repeated measures ANOVA was performed for each drug separately, with dose as within-subject variable (and possibly stimulus duration 
Fig. 1 The effects of SCOP $(0.1,0.3$, and $1 \mathrm{mg} / \mathrm{kg}, \mathrm{IP})$ and $\operatorname{BIP}(1,3$, and $10 \mathrm{mg} / \mathrm{kg}$, IP) on a FR5 schedule of reinforcement. a, b Inter-response time. SCOP slowed sensorimotor responding at a dose of 0.3 and $1 \mathrm{mg} / \mathrm{kg}$. BIP slowed sensorimotor responding at a dose of $10 \mathrm{mg} / \mathrm{kg}$. Data represent mean (+SEM). Asterisks indicate differences from vehicle condition $\left({ }^{*} P<0.05 ;{ }^{* *} P<0.01\right)$

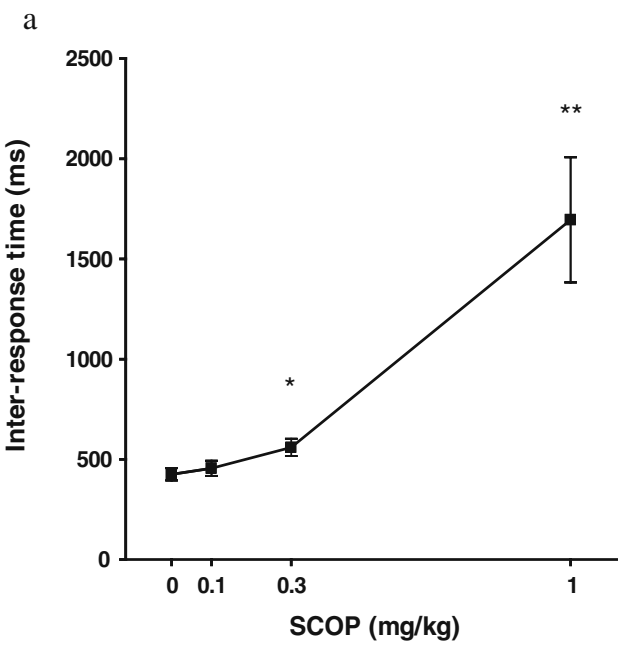

or delay). Hence, drug effects of SCOP and BIP were compared with their own vehicle condition: i.e., SCOP with saline and BIP with Milli-Q. For the analysis of the attention task and the DNMTP, stimulus duration and delay were added as additional within-subject variables, respectively. In case a significant dose $\times$ stimulus duration or dose $\times$ delay interaction was reported, several repeated measures ANOVAs were run separately for stimulus duration or delay, respectively. One exception was the measure response time; here, data were averaged for each animal and collapsed across stimulus duration or delay. Differences from vehicle conditions were always examined with a least significant difference post hoc test. Due to some mechanical issues, occasionally data of nine rats were used for analysis.

\section{Results}

Fixed ratio (five) task

Three rats failed to complete 60 trials within 30 min after a dose of $1 \mathrm{mg} / \mathrm{kg}$ SCOP. Figure 1 shows the effects of SCOP and BIP on inter-response time in a FR5 schedule of reinforcement. In the mixed model ANOVA, the withinsubject effect of dose on inter-response time varied per level of drug (dose $\times$ drug interaction effect; $F(3,48)=10.77 ; P<$ 0.001 ). Therefore two separate repeated measures ANOVAs for the different levels of drug were performed. For the group treated with SCOP, inter-response time in the FR5 task was increased (main effect of dose; $F(3,24)=12.82 ; P<$ 0.001 ; see Fig. 1a). Post hoc analysis showed that the 0.3 $(P<0.05)$ and $1 \mathrm{mg} / \mathrm{kg}(P<0.01)$ doses slowed responding. In the group treated with BIP, there was an increase in FR5 inter-response time (main effect of dose; $F(3,24)=7.80 ; P<$ 0.01 ; see Fig. 1b). Post hoc analysis indicated only an effect of the high $10 \mathrm{mg} / \mathrm{kg}$ dose $(P<0.01)$
Progressive ratio (ten) task

Figure 2 shows the effects of SCOP and BIP on breakpoint and inter-response time on a PR10 schedule of reinforcement. In the mixed model ANOVA, the within-subject effect of dose on breakpoint did not vary per level of drug (no dose $\times$ drug interaction effect; $F(2,36)=0.77$, n.s.). Furthermore, breakpoint was differentially affected by dose (main effect of dose; $F(2,36)=5.57 ; P<0.01$ ). The between-subject analysis of drug showed that SCOP and BIP differentially affected breakpoint (main effect of drug; $F(1,18)=5.93 ; P<0.05)$. Therefore, two separate repeated measures ANOVAs for the different levels of drug were performed. For the group treated with SCOP, breakpoint in the PR10 task was reduced (main effect of dose; $F(2,18)=$ 3.91; $P<0.05$; see Fig. 2a). Post hoc analysis showed an effect of the $1 \mathrm{mg} / \mathrm{kg}$ dose $(P<0.05)$. For the group treated with BIP, no change in breakpoint (no main effect of dose; $F(2,18)=2.10$, n.s.; see Fig. $2 b$ ) was found.

In the mixed model ANOVA, the within-subject effect of dose on inter-response time did not vary per level of drug (no dose $\times$ drug interaction effect; $F(2,36)=0.38$, n.s.; see Figs. $2 \mathrm{c}$ and $2 \mathrm{~d}$ ). The within-subject analysis of dose was not significant (no main effect of dose; $F(2,36)=3.04$, n.s.), which means that the different dose conditions also did not change inter-response time. The between-subject analysis of drug showed that SCOP and BIP did not differentially affect inter-response time (no main effect of drug; $F(1,18)=0.32$, n.s.).

\section{Attention task}

Figure $3 \mathrm{a}, \mathrm{b}$ shows the effects of SCOP and BIP on percentage correct in the attention task. In the mixed model ANOVA, the within-subject effect of dose on percentage correct did not vary per level of drug and stimulus duration (no dose $\times$ drug $\times$ stimulus duration interaction effect; 
Fig. 2 The effects of SCOP $(0.3$ and $1 \mathrm{mg} / \mathrm{kg}$, IP) and BIP (3 and $10 \mathrm{mg} / \mathrm{kg}$, IP) on a PR10 schedule of reinforcement. $\mathbf{a}, \mathbf{b}$ Breakpoint. SCOP decreased food motivation at a dose of $1 \mathrm{mg} / \mathrm{kg}$. BIP did not have an effect on food motivation. $\mathbf{c}, \mathbf{d}$ Inter-response time. SCOP slowed sensorimotor responding at a dose of $1 \mathrm{mg} / \mathrm{kg}$. BIP did not have an effect on sensorimotor responding. Data represent mean (+SEM). Asterisks indicate differences from vehicle condition $(* P<0.05)$

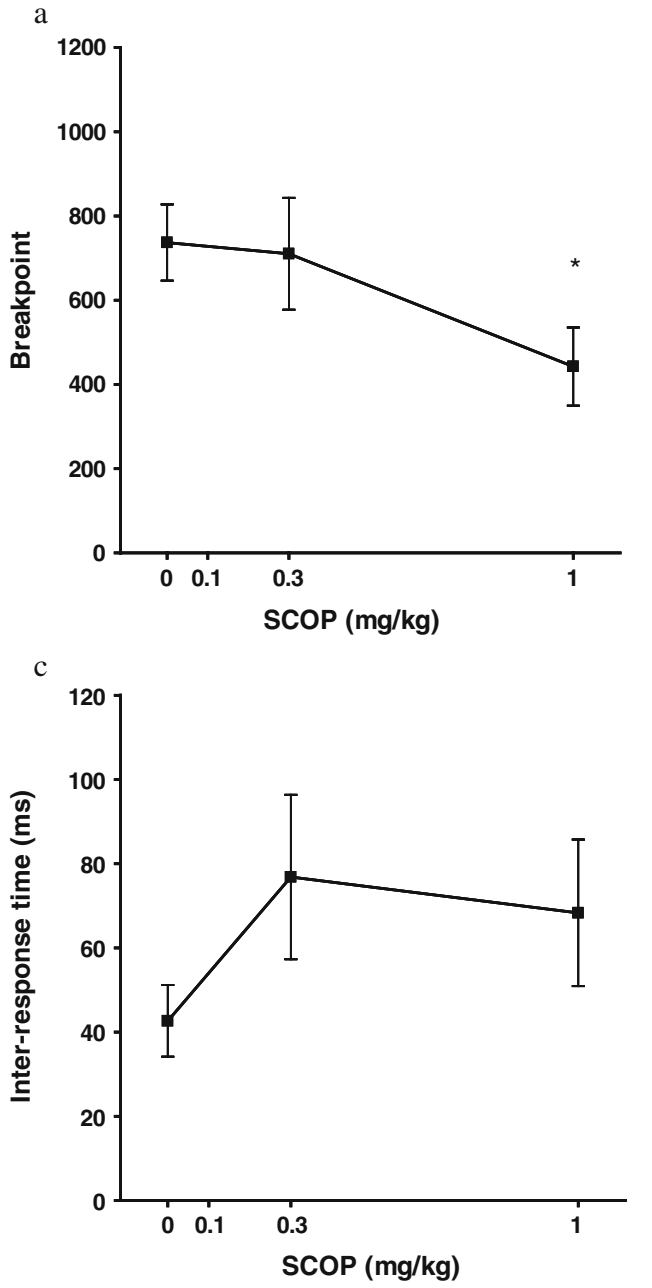

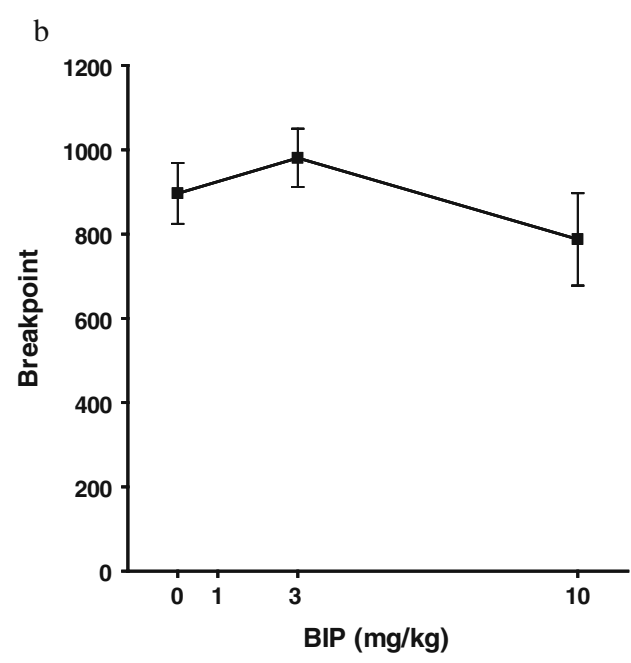

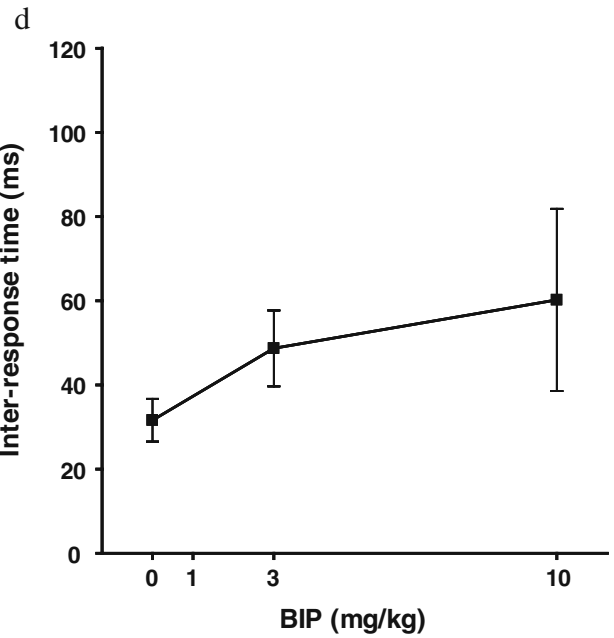

$F(4,68)=0.75$, n.s.). However, the within-subject effect of dose on percentage correct did vary per level of drug (dose $\times$ drug interaction effect; $F(2,34)=7.96 ; P<0.01)$. The withinsubject effect of stimulus duration on percentage correct was also different per level of drug (stimulus duration $\times$ drug interaction effect; $F(2,34)=3.82 ; P<0.05)$. Therefore separate repeated measures ANOVAs for the two levels of drug were performed. In the group treated with SCOP, the withinsubject effect of stimulus duration on percentage correct was not different per level of dose (no stimulus duration $\times$ dose interaction effect; $F(4,36)=0.83$, n.s.; see Fig. 3a). There was a reduction in percentage correct responses with shorter stimulus durations (main effect of stimulus duration; $F(2,18)=40.06 ; P<0.001)$. SCOP decreased percentage correct responses in the attention task (main effect of dose; $F(2,18)=20.55 ; P<0.001)$. Post hoc analysis showed that at a dose of $0.3 \mathrm{mg} / \mathrm{kg}$ SCOP lowered percentage correct score as compared with the vehicle condition $(P<0.01)$. In the group treated with BIP, the within-subject effect of stimulus duration on percentage correct was not different per level of dose (no stimulus duration $\times$ dose interaction effect;
$F(4,32)=0.36$, n.s.; see Fig. 3b). Moreover, shorter stimulus durations reduced percentage correct (main effect of stimulus duration; $F(2,16)=149.29 ; P<0.001)$. BIP treatment did not affect the measure percentage correct (no main effect of dose; $F(2,16)=2.69$, n.s. $)$.

Figure 3c, d shows the effects of SCOP and BIP on percentage omissions in the attention task. In the mixed model ANOVA, the within-subject effect of dose on percentage omissions did not vary per level of drug and stimulus duration (no dose $\times \operatorname{drug} \times$ stimulus duration interaction effect; $F(4,68)=0.98$, n.s. $)$. The within-subject effect of stimulus duration on percentage omissions was also not different per level of drug (no stimulus duration $\times$ drug interaction effect; $F(2,34)=1.16$, n.s.). In contrast, the within-subject effect of dose on percentage omissions did vary per level of drug (dose $\times$ drug interaction effect; $F(2,34)=6.98 ; P<0.01)$. Therefore, separate repeated measures ANOVAs for the two levels of drug were performed. In the group treated with SCOP, the withinsubject effect of stimulus duration on percentage omissions was not different per level of dose (no stimulus duration $\times$ dose 
Fig. 3 The effects of SCOP $(0.1,0.3 \mathrm{mg} / \mathrm{kg}, \mathrm{IP})$ and BIP $(3,10 \mathrm{mg} / \mathrm{kg}$, IP) on performance measures in the attention task. a, b Percentage correct responses. SCOP decreased accuracy independent of stimulus duration at a dose of $0.3 \mathrm{mg} / \mathrm{kg}$. BIP did not have an effect on accuracy. c, d Percentage omissions. SCOP increased response omissions independent of stimulus duration at a dose of $0.3 \mathrm{mg} / \mathrm{kg}$. BIP did not have an effect on response omissions. $\mathbf{e}, \mathbf{f}$ Response time. SCOP slowed sensorimotor responding at a dose of $0.3 \mathrm{mg} / \mathrm{kg}$. BIP did not have an effect on sensorimotor responding. Data represent mean (+SEM). Asterisks indicate differences from vehicle condition $(* * P<0.01$; $* * * P<0.001)$ $\mathrm{a}$

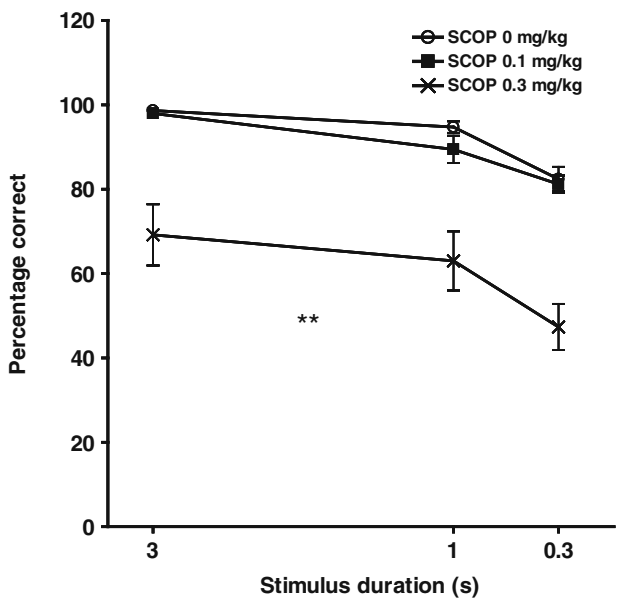

c

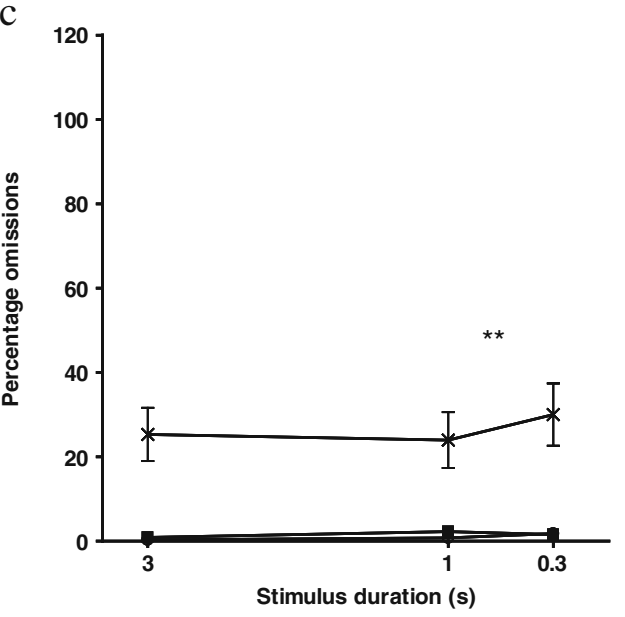

e

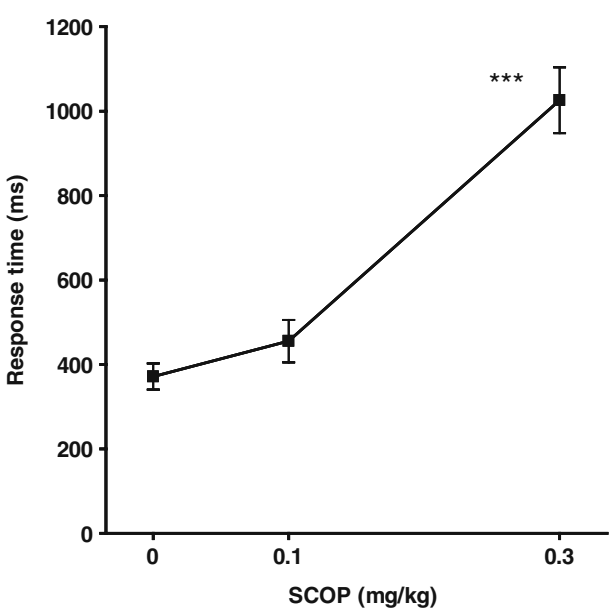

b

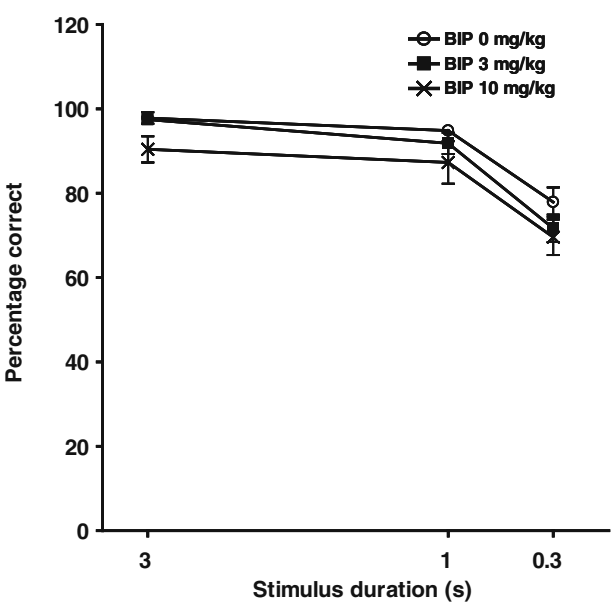

d

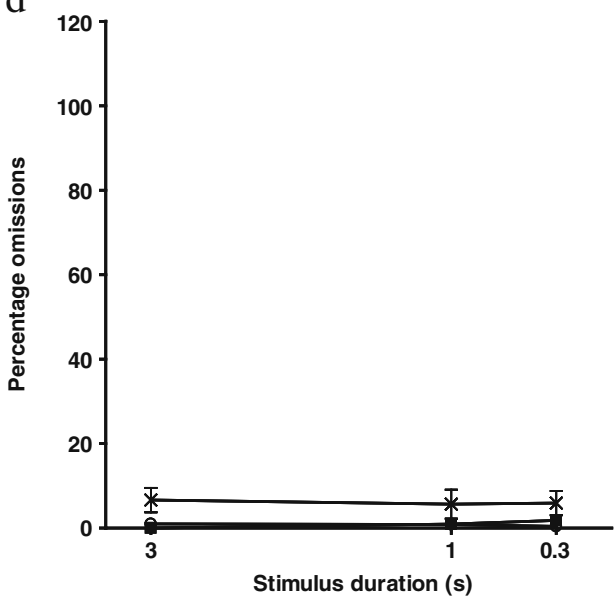

f

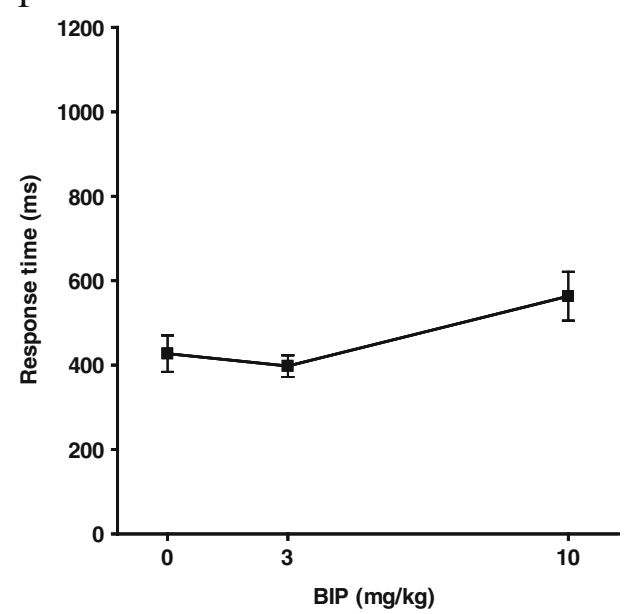

interaction effect; $F(4,36)=0.95$, n.s.; see Fig. 3c). There was no change in percentage omissions with shorter stimulus durations (no main effect of stimulus duration; $F(2,18)=$ 1.70, n.s.). SCOP enhanced percentage omissions in the attention task (main effect of dose; $F(2,18)=15.66 ; P<$ $0.001)$. Post hoc analysis showed that at a dose of $0.3 \mathrm{mg} / \mathrm{kg}$
SCOP augmented percentage omissions as compared with the vehicle condition $(P<0.01)$. In the group treated with BIP, the within-subject effect of stimulus duration on percentage omissions was not different per level of dose (no stimulus duration $\times$ dose interaction effect; $F(4,32)=$ 0.61 , n.s.; see Fig. 3d). Moreover, shorter stimulus durations 
had no effect on percentage omissions (no main effect of stimulus duration; $F(2,16)=0.01$, n.s.). BIP treatment did not affect the measure percentage omissions (no main effect of dose; $F(2,16)=3.31$, n.s.).

Figure $3 \mathrm{e}, \mathrm{f}$ shows the effects of SCOP and BIP on response time in the attention task. The within-subject effect of dose on response time was found to vary per level of drug (dose $\times$ drug interaction effect; $F(2,34)=5.59 ; P<$ 0.01). Therefore, separate repeated measures ANOVAs for the two levels of drug were performed. In the group treated with SCOP, response time was slowed (main effect of dose; $F(2,18)=27.74 ; P<0.001$; see Fig. 3e). Post hoc analysis showed an effect of the $0.3 \mathrm{mg} / \mathrm{kg}$ dose $(P<0.001)$. In the BIP group, response time was also significantly changed (main effect of dose; $F(2,16)=4.28 ; P<0.05$; see Fig. 3f). However, post hoc analysis revealed no differences between vehicle and dose conditions.

Figure $4 a, b$ shows the effects of SCOP and BIP on SI in the attention task. In the mixed model ANOVA, the within-subject effect of dose on SI did not vary per level of drug and stimulus duration (no dose $\times$ drug $\times$ stimulus duration interaction effect; $F(4,68)=1.34$, n.s.). However, the within-subject effect of dose on SI did vary per level of drug (dose $\times$ drug interaction effect; $F(2,34)=$ $6.30 ; P<0.01)$. The within-subject effect of stimulus duration on SI was also different per level of drug (stimulus duration $\times$ drug interaction effect; $F(2,34)=$ 4.63; $P<0.05)$. Therefore, separate repeated measures ANOVAs for the two levels of drug were performed. In the group treated with SCOP, the within-subject effect of stimulus duration on SI varied per level of dose (stimulus duration $\times$ dose interaction effect; $F(4,36)=2.82 ; P<0.05$; see Fig. 4a). Hence, separate repeated measures ANOVAs were performed per level of stimulus duration. Post hoc analyses showed that SCOP reduced SI at al stimulus duration conditions. In the group treated with BIP, the within-subject effect of stimulus duration on SI was not different per level of dose (no stimulus duration $\times$ dose interaction effect; $F(4,32)=0.12$, n.s.; see Fig. $4 b)$. Shorter stimulus durations reduced SI (main effect of stimulus duration; $F(2,16)=151.65 ; P<0.001)$. BIP treatment did not affect the measure SI (no main effect of dose; $F(2,16)=1.15$, n.s.).

Figure $4 \mathrm{c}, \mathrm{d}$ shows the effects of SCOP and BIP on index $Y$ in the attention task. In the mixed model ANOVA, the within-subject effect of dose on response bias did not vary per level of drug and stimulus duration (no dose $\times$ drug $\times$ stimulus duration interaction effect; $F(4,68)=0.68$, n.s.). The within-subject effect of stimulus duration on index $Y$ was also not different per level of drug (no stimulus duration $\times$ drug interaction effect; $F(2,34)=0.11$, n.s.). The within-subject effect of dose on response bias did not vary per level of drug (no dose $\times$ drug interaction effect;
$F(2,34)=1.53$, n.s.). Index $Y$ was differentially affected by dose (main effect of dose; $F(2,34)=4.00 ; P<0.05$ ). Post hoc analysis showed that the highest dose conditions of SCOP and BIP augmented index $Y$ as compared with the vehicle condition $(P<0.05)$. However, the between-subject analysis of drug showed that SCOP and BIP did not differentially affect index $Y$ (no main effect of drug; $F(1,17)=3.13$, n.s.). Because we sought to determine which drug was responsible for the main effect of dose in the mixed model analysis, we did separate repeated measures ANOVAs per level of drug. In the group treated with SCOP, the within-subject effect of stimulus duration on index $Y$ was not different per level of dose (no stimulus duration $\times$ dose interaction effect; $F(4,36)=0.32$, n.s.; see Fig. 4c). There was a change in index $Y$ with shorter stimulus durations (main effect of stimulus duration; $F(2,18)=12.40$; $P<0.001$ ). SCOP did not affect the index $Y$ measure (no main effect of dose; $F(2,18)=3.35$, n.s.). In the group treated with BIP, the within-subject effect of stimulus duration on SI was not different per level of dose (no stimulus duration $\times$ dose interaction effect; $F(4,32)=1.79$, n.s.; see Fig. 4d). Shorter stimulus durations reduced SI (main effect of stimulus duration; $F(2,16)=15.22 ; P<$ 0.001 ). BIP treatment did not affect the measure SI (no main effect of dose; $F(2,16)=1.48$, n.s.).

\section{Delayed nonmatching to position}

Figure $5 \mathrm{a}, \mathrm{b}$ shows the effects of SCOP and BIP on percentage correct in the DNMTP task. In the mixed model ANOVA on percentage correct, the dose effect varied per level of delay and drug (dose $\times$ delay $\times$ drug interaction effect; $F(8,144)=3.69 ; P<0.01)$. Therefore, separate repeated measures ANOVAs for the two levels of drug were performed. In the group treated with SCOP, the within-subject effect of delay on percentage correct was different per level of dose (delay $\times$ dose interaction effect; $F(8,72)=3.84 ; P<0.01$; see Fig. 5a). Hence, additional repeated measures ANOVAs were performed per level of delay. SCOP affected percentage correct at the 0-, 2-, 4-, and 8-s delay conditions (main effect of dose; F's $(2,18)>$ 9.23; $P<0.01)$. Post hoc analyses showed that a dose of $0.3 \mathrm{mg} / \mathrm{kg}$ was different from the vehicle condition. In addition, a dose of $0.1 \mathrm{mg} / \mathrm{kg}$ also affected accuracy performance at the 8-s delay condition. SCOP had no effect on percentage correct at 16-s delay condition (no main effect of dose; $F(2,18)=0.31$, n.s.).

In the group treated with BIP, the within-subject effect of delay on percentage correct was different per level of dose (delay $\times$ dose interaction effect; $F(8,72)=2.30 ; P<0.05$; see Fig. 5b). Hence, separate repeated measures ANOVAs were performed per level of delay. BIP did not affect percentage correct at the 0- and 16-s delay condition (no main effect of 
Fig. 4 The effects of SCOP $(0.1,0.3 \mathrm{mg} / \mathrm{kg}, \mathrm{IP})$ and BIP $(3,10 \mathrm{mg} / \mathrm{kg}, \mathrm{IP})$ on signal detection theory measures in the attention task. a, b Sensitivity Index (SI). SCOP decreased discriminability dependent of stimulus duration at a dose of $0.3 \mathrm{mg} / \mathrm{kg}$. BIP did not have an effect on discriminability. $\mathbf{c}, \mathbf{d}$ Index $Y$. Neither SCOP nor BIP had an effect on response bias. Data represent mean $(+\mathrm{SEM})$. Asterisks indicate differences from vehicle condition $\left({ }^{*} P<0.05 ; * * P<0.01\right)$
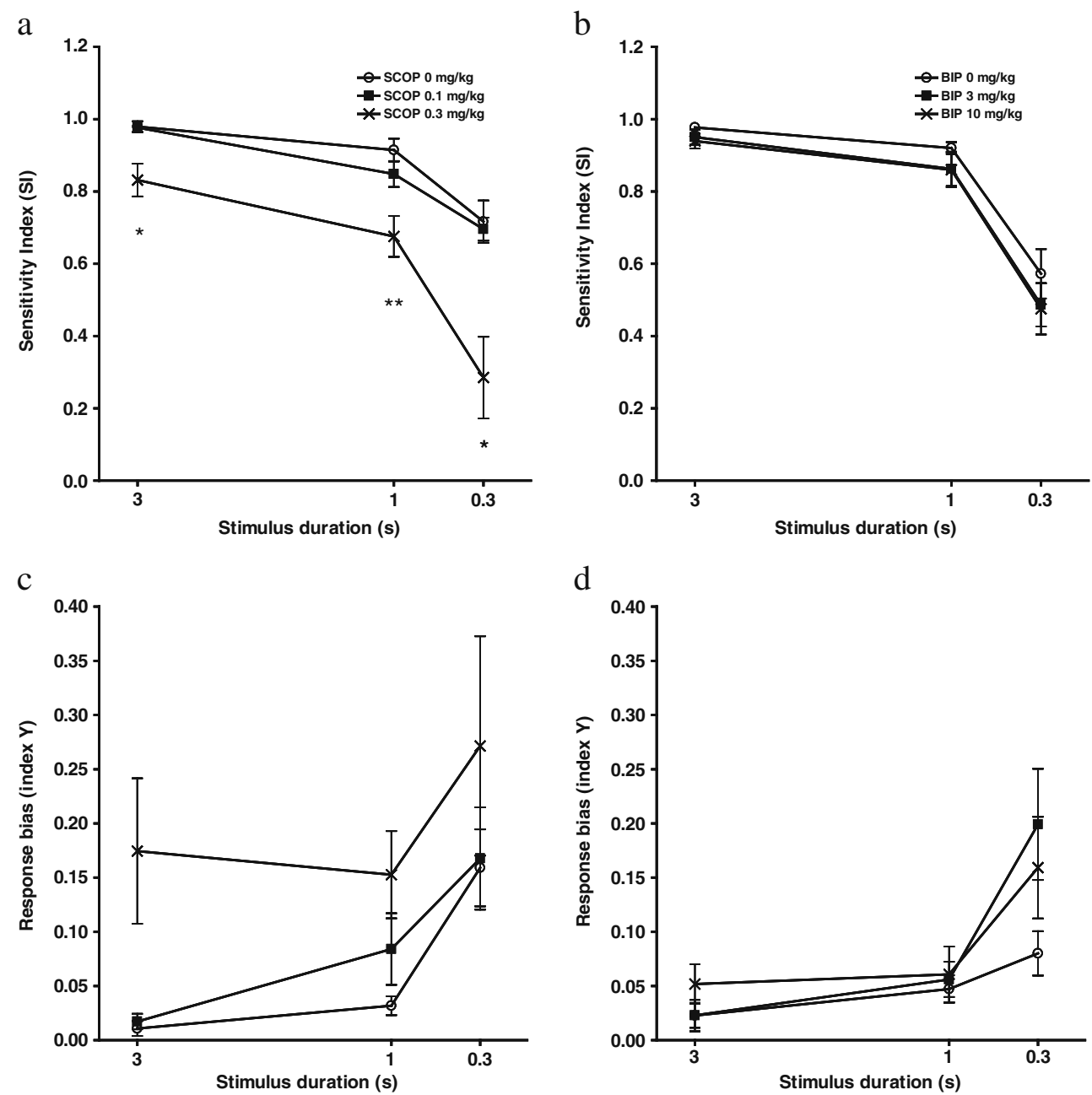

d

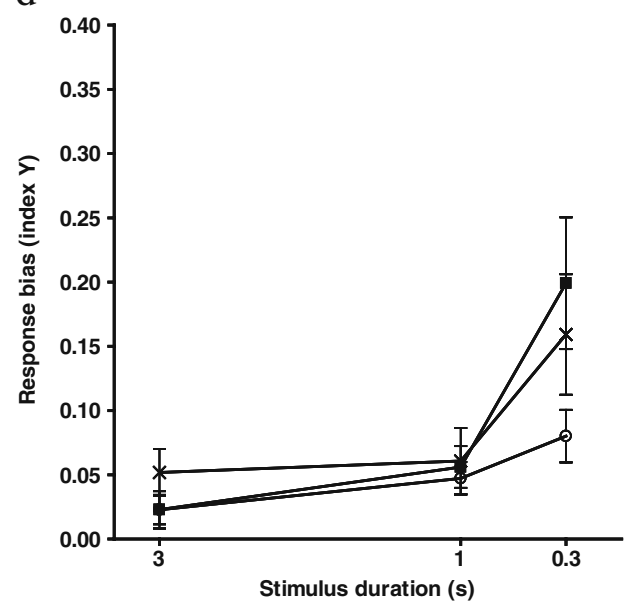

dose; $F$ 's $(2,18)<2.95$, n.s.). However, BIP impaired percentage correct in trials with a 2-, 4-, and 8-s delay (main effect of dose; $F$ 's $(2,18)>5.84 ; P<0.05)$. Separate post hoc analyses demonstrated that the $3 \mathrm{mg} / \mathrm{kg}$ dose decreased percentage correct as compared with the vehicle condition.

Figure $5 \mathrm{c}, \mathrm{d}$ shows the effects of SCOP and BIP on response time in the DNMTP task. The within-subject effect of dose on response time did not vary per level of drug (no dose $\times$ drug interaction effect; $F(2,36)=2.06$, n.s.). There was no effect of dose (no main effect of dose; $F(2,36)=$ 1.06 , n.s.). SCOP and BIP did not differentially affect response time (no main effect of drug; $F(1,18)=1.44$, n.s.).

Figure $6 \mathrm{a}, \mathrm{b}$ shows the effects of SCOP and BIP on SI in the DNMTP task. In the mixed model ANOVA on SI, the dose effect varied per level of delay and drug (dose $\times$ delay $\times$ drug interaction effect; $F(8,144)=3.68 ; P<0.01)$. Therefore, separate repeated measures ANOVAs for the two levels of drug were performed. In the group treated with SCOP, the within-subject effect of delay on SI was different per level of dose (delay $\times$ dose interaction effect; $F(8,72)=$ 3.84; $P<0.01$; see Fig. 6a). Hence, additional repeated measures ANOVAs were performed per level of delay. In the
$0-, 2-, 4-$, and 8 -s delay trials a main effect of dose was found $(F$ 's $(2,18)>9.23 ; P<0.01)$. Separate post hoc analyses showed that at a dose of $0.3 \mathrm{mg} / \mathrm{kg}$ SCOP reduced SI as compared with the vehicle condition. In addition a dose of $0.1 \mathrm{mg} / \mathrm{kg}$ also affected performance at the 8-s delay condition. SCOP had no effect on SI in trials which used a 16 -s delay (no main effect of dose; $F(2,18)=0.31$, n.s.).

In the group treated with BIP, the within-subject effect of delay on SI was different per level of dose (delay $\times$ dose interaction effect; $F(8,72)=2.30 ; P<0.05$; see Fig. 6 b). Hence, separate repeated measures ANOVAs were performed per level of delay. In trials with a 0 - or 16-s delay BIP did not affect SI (no main effect of dose; F's(2, 18)< 2.95 , n.s.). BIP did influence SI in trials a 2-, 4-, and 8-s delay (main effect of dose; $F$ 's $(2,18)>5.84 ; P<0.05$ ). Post hoc analysis revealed that the $3 \mathrm{mg} / \mathrm{kg}$ dose decreased SI as compared with the vehicle condition $(P<0.01)$.

Figure $6 \mathrm{c}, \mathrm{d}$ shows the effects of SCOP and BIP on index $Y$ in the DNMTP task. In the mixed model ANOVA, the within-subject effect of dose on response bias did not vary per level of drug and delay (no dose $\times$ drug $\times$ delay interaction effect; $F(8,136)=1.13$, n.s.). The within-subject 
Fig. 5 The effects of SCOP $(0.1,0.3 \mathrm{mg} / \mathrm{kg}, \mathrm{IP})$ and BIP $(1,3 \mathrm{mg} / \mathrm{kg}$, IP) on performance measures in delayed nonmatching to position. $\mathbf{a}, \mathbf{b}$ Percentage correct responses. SCOP decreased accuracy delay-dependently at a dose of 0.1 and $0.3 \mathrm{mg} / \mathrm{kg}$. BIP reduced accuracy delaydependently at a dose of $3 \mathrm{mg} / \mathrm{kg}$. c, d Response time. Neither SCOP nor BIP had an effect on sensorimotor responding. Data represent mean (+SEM). Asterisks indicate differences from vehicle condition $(* P<0.05$; $* * P<0.01 ; * * * P<0.001)$ a
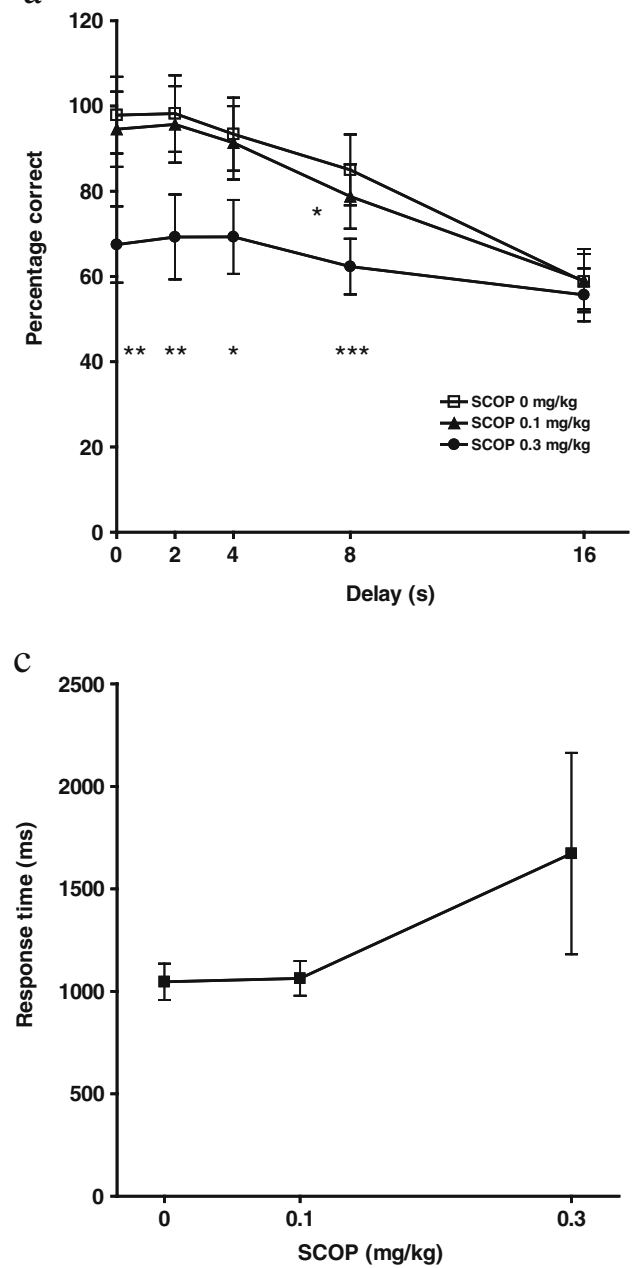

b

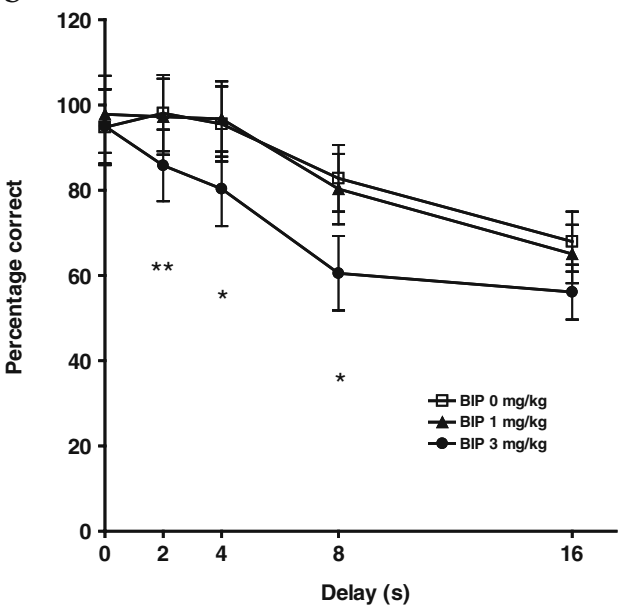

d

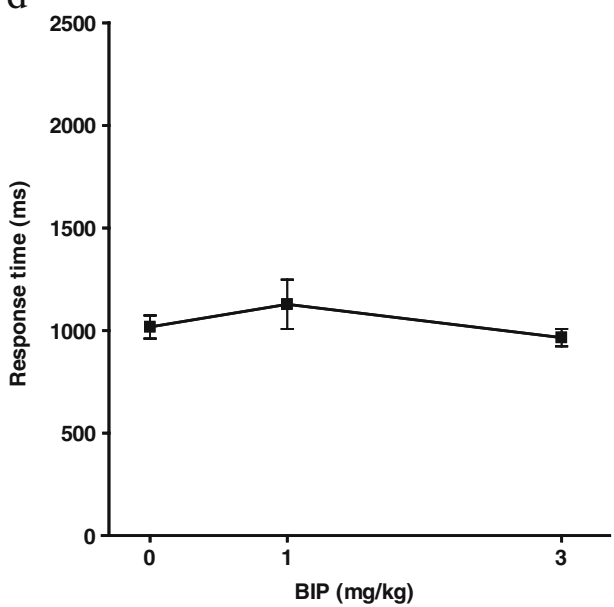

effect of delay on index $Y$ was also not different per level of drug (no delay $\times$ drug interaction effect; $F(4,68)=0.43$, n.s.). Moreover, the within-subject effect of dose on response bias did not vary per level of drug (no dose $\times$ drug interaction effect; $F(2,34)=3.06$, n.s.). The within-subject effect of dose on index $Y$ was also not different per level of delay (no dose $\times$ delay interaction effect; $F(8,136)=1.78$, n.s.). Index $Y$ was differentially affected by dose (main effect of dose; $F(2,34)=22.24 ; P<0.001)$. The between-subject analysis of drug showed that SCOP and BIP did differentially affect index $Y$ (main effect of drug; $F(1,17)=4.49 ; P<0.05$ ). Therefore, separate repeated measures ANOVAs for the two levels of drug were performed. In the group treated with SCOP, the within-subject effect of delay on response bias was not different per level of dose (no delay $\times$ dose interaction effect; $F(8,64)=1.67$, n.s.; see Fig. 6c). Index $Y$ increased with longer delays (main effect of delay; $F(4,32)=12.28 ; P<$ 0.001). SCOP enhanced response bias in the DNMTP task (main effect of dose; $F(2,16)=11.62 ; P<0.01$ ). Post hoc analysis showed that at a dose of $0.3 \mathrm{mg} / \mathrm{kg}$ SCOP augmented index $Y$ as compared with the vehicle condition $(P<0.01)$. In the group treated with BIP, the within-subject effect of delay on index $Y$ was not different per level of dose (no delay $\times$ dose interaction effect; $F(8,72)=1.29$, n.s.; see Fig. 6d). Moreover, with longer delays response bias was increased (main effect of delay; $F(4,36)=18.92 ; P<0.001$ ). BIP was shown to increase response bias in the DNMTP task (main effect of dose; $F(2,18)=12.55 ; P<0.001)$. Post hoc analysis showed that at a dose of $3 \mathrm{mg} / \mathrm{kg}$ BIP augmented index $Y$ as compared with the vehicle condition $(P<0.01)$.

\section{Discussion}

The main objective of the current study was to compare the effects of the nonselective muscarinic antagonist SCOP and the $\mathrm{m} 1$ antagonist BIP after systemic injections on different aspects of operant behavior: sensorimotor responding (FR5), food motivation (PR10), attention and short-term memory (DNMTP). The direct comparison of both drugs allowed evaluation with respect to the usability of BIP, as opposed to SCOP, as a suitable model of cholinergic memory dysfunction. Since BIP is relatively selective for $\mathrm{m} 1$ receptors which can be found predominantly in brain 
Fig. 6 The effects of SCOP $(0.1,0.3 \mathrm{mg} / \mathrm{kg}, \mathrm{IP})$ and $\operatorname{BIP}(1,3 \mathrm{mg} / \mathrm{kg}, \mathrm{IP})$ on signal detection measures in delayed non-matching to position. a, b Sensitivity Index (SI). SCOP decreased discriminability delay-dependently at a dose of 0.1 and $0.3 \mathrm{mg} / \mathrm{kg}$. BIP reduced discriminability delay-dependently at a dose of $3 \mathrm{mg} / \mathrm{kg}$. c, d Index $Y$. SCOP decreased response bias delay-independently at a dose of $0.3 \mathrm{mg} / \mathrm{kg}$. BIP reduced response bias delayindependently at a dose of $3 \mathrm{mg} / \mathrm{kg}$. Data represent mean (+SEM). Asterisks indicate differences from vehicle condition $(* P<0.05$ $\left.{ }^{* *} P<0.01 ;{ }^{* * *} P<0.001\right)$ a

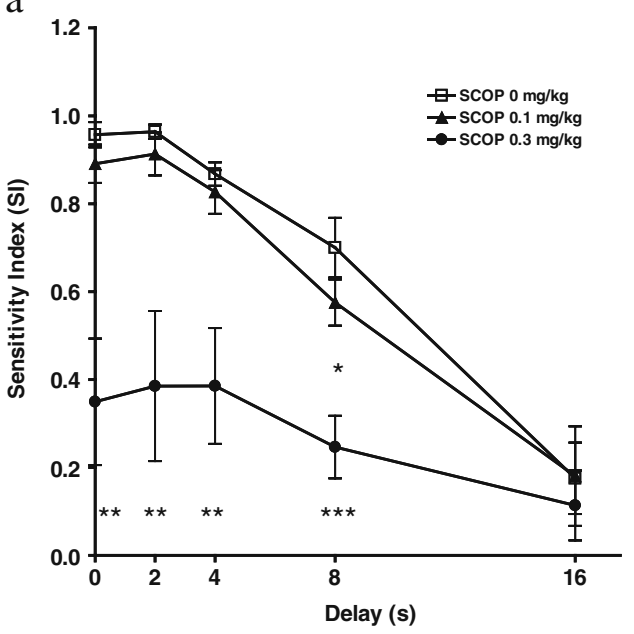

c

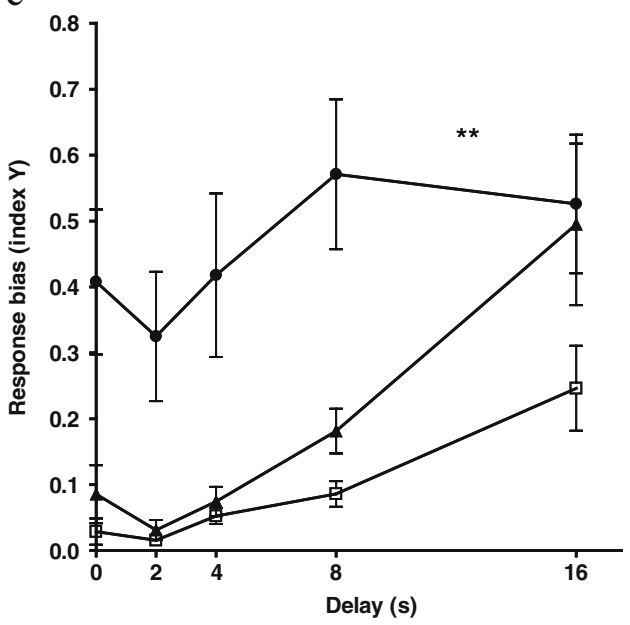

b

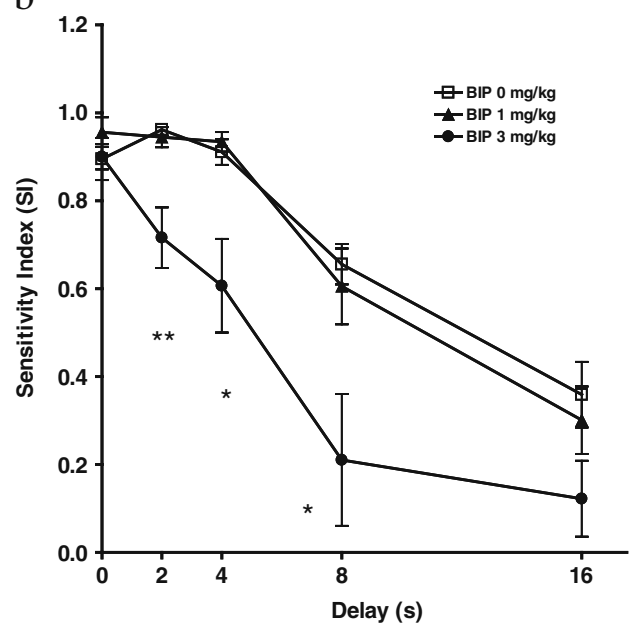

d

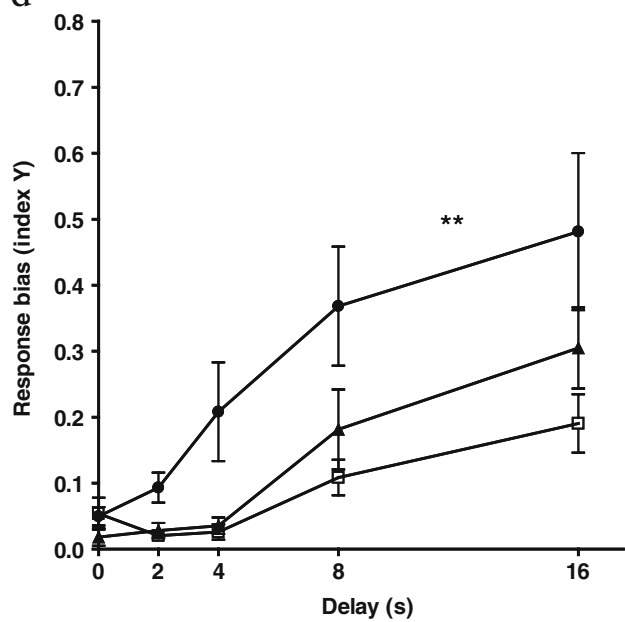

areas involved in learning and memory (Caulfield 1993; Volpicelli and Levey 2004), we expected also a more selective effect of BIP on cognition and behavioral performance. In Table 1 an overview is given of the effects of both drugs on the various behavioral measures. A wide range of behavioral impairments were found after SCOP; cognitive and peripheral effects were not dissociable on basis of dose conditions. Moreover, performance deficits in the short-term memory task were of a nonmnemonic nature. In contrast, BIP more selectively impaired DNMTP performance at a dose of $3 \mathrm{mg} / \mathrm{kg}$, at which no peripheral effects were found; sensorimotor responding was slowed after the $10 \mathrm{mg} / \mathrm{kg}$ dose.

Of note, some caution should be taken with respect to the selectivity of muscarinic (ant)agonists. Due to the highly conserved nature of the orthosteric binding site amongst muscarinic receptors, drugs that target these can be characterized as possessing relative rather than absolute receptor subtype selectivity. These issues should be borne in mind when trying to attribute effects of these drugs to specific muscarinic receptor subtypes. BIP for instance has about tenfold higher affinity for $\mathrm{m} 1$ as compared with $\mathrm{m} 2$ m5 receptors (see Bolden et al. 1992; Katayama et al. 1990). The pharmacokinetic characteristics of BIP are quite favorable; cerebellar levels after a dose of $3.2 \mathrm{mg} / \mathrm{kg}$ (IV) have been reported to be about ten times higher as plasma levels (see Nakashima et al. 1993; Syvälahti et al. 1988; Yokogawa et al. 1990; Yokogawa et al. 1992). Regardless, BIP is currently the drug of choice for making a direct comparison with SCOP, particularly as it is approved for use in humans and therefore suitable for translational research. Some other drugs that target the muscarinic $\mathrm{m} 1$ receptor cannot be used in systemic injections because they do not cross the blood-brain barrier (e.g., pirenzepine).

\section{Sensorimotor responding}

Both SCOP and BIP were found to slow sensorimotor responding on a FR5 schedule of reinforcement, although at a different dose $(0.3$ and $1 \mathrm{mg} / \mathrm{kg}$ for SCOP and $10 \mathrm{mg} / \mathrm{kg}$ for BIP, see Fig. 1). Although both SCOP and BIP increased inter-response time in the FR5 task it should be 
Table 1 An overview of the effects of SCOP and BIP on sensorimotor responding, food motivation, attention, and short-term memory

Doses are given in milligrams per kilogram, IP

Abbreviations: FR5 fixed ratio 5, PR10 progressive ratio $10, A T$ attention task, DNMTP delayed nonmatching to position, $S C O P$ scopolamine hydrobromide, $B I P$ biperiden, $D D$ delay-dependent effect, $D I$ delay-independent effect, equal sign no change, upward arrow increase, downward arrow decrease

\begin{tabular}{lll}
\hline & Drug & \\
\hline Behavioral task & SCOP & BIP \\
FR5 & Inter-response time $\uparrow(0.3,1)$ & Inter-response time $\uparrow(10)$ \\
PR10 & Breakpoint $\downarrow(1)$ & Breakpoint $=$ \\
& Inter-response time $=$ & Inter-response time $=$ \\
AT & Percentage correct $\downarrow(0.3, \mathrm{DI})$ & Percentage correct $=$ \\
& Percentage omissions $\uparrow(0.3, \mathrm{DI})$ & Percentage omissions $=$ \\
& Response time $\uparrow(0.3)$ & Response time $=$ \\
& Sensitivity index $\downarrow(0.3, \mathrm{DD})$ & Sensitivity index $=$ \\
& Index $Y=$ & Index $Y=$ \\
DNMTP & Percentage correct $\downarrow(0.1,0.3, \mathrm{DD})$ & Percentage correct $\downarrow$ (3, DD) \\
& Response time $=$ & Response time $=$ \\
& Sensitivity index $\downarrow(0.1,0.3, \mathrm{DD})$ & Sensitivity index $\downarrow$ (3, DD) \\
& Index $Y \uparrow(0.3, \mathrm{DI})$ & Index $Y \uparrow(3, \mathrm{DI})$ \\
\hline
\end{tabular}

noted that the effects of BIP were smaller as compared with SCOP. BIP, at a dose of $10 \mathrm{mg} / \mathrm{kg}$, slowed FR5 responses by $26 \%$ as compared with the vehicle condition. SCOP, at a dose of 0.3 and $1 \mathrm{mg} / \mathrm{kg}$, increased inter-response time by about $32 \%$ and $298 \%$, respectively. In FR tasks, SCOP has generally been found to decrease lever presses independent of reward type (dry vs. wet, Hodges et al. 2009). However, the minimal effective dose reported in these studies does show quite some variability $(0.005-1.0 \mathrm{mg} / \mathrm{kg}$ IP, Hodges et al. 2009; Pradhan and Roth 1968). In a brightness discrimination task, BIP $(0.25-2 \mathrm{mg} / \mathrm{kg}, \mathrm{SC})$ was found to reduce the rate of reinforcement (Liu 1996). Furthermore, intracerebroventricular infusion of the $\mathrm{ml}$ antagonist pirenzepine $(10,30 \mu \mathrm{g}$ in $2.5 \mu \mathrm{L})$ increased the sample latency in a DNMTP task (Aura et al. 1997), although a reduction in response latency has also been reported (Andrews et al. 1994).

These results suggest that the effect of systemic administration of SCOP and BIP on sensorimotor responding is at least partially mediated by the $\mathrm{ml}$ receptor. However, from the present data it cannot be deduced whether this change in sensorimotor responding is caused by central or peripheral $\mathrm{m} 1$ blockade, or both. For instance, in the periphery $\mathrm{m} 1$ receptors have been found in abundance in rat sympathetic ganglia such as the superior cervical ganglion (Caulfield and Birdsall 1998). However, the effects of SCOP and BIP on sensorimotor responding could also result from an interaction between $\mathrm{ml}$ and striatal dopaminergic signaling (De Klippel et al. 1993; Gerber et al. 2001).

Food motivation

SCOP (1 $\mathrm{mg} / \mathrm{kg}$ ) was found to decrease food motivation and slow sensorimotor responding on a PR10 schedule, whereas BIP (3 and $10 \mathrm{mg} / \mathrm{kg}$ ) did not have an effect on these measures (see Fig. 2). This is in accordance with studies in monkeys performing a PR schedule where SCOP reduced the number of obtained reinforcements (Spinelli et al. 2006; Taffe et al. 1999). Food and water intake in rats was found to be diminished after SCOP administration (Hodges et al. 2009; Pradhan and Roth 1968). To the best of our knowledge, neither BIP, nor any other $\mathrm{m} 1$ antagonists have been tested in paradigms assessing food motivation and/or free feeding behavior. Although it is possible that a higher dose of BIP would have yielded a reduction in motivation, this dose is comparable to dose conditions used in other behavioral studies (Jones and Shannon 2000; Kimura et al. 1999; Liu 1996; Myers et al. 2002; Myhrer et al. 2008; Roldán et al. 1997; Sipos et al. 1999; 2001).

Again, it cannot be decisively determined whether the decrement in motivation for food after administration of SCOP is a central or a peripheral effect. SCOP has been known to induce "dry mouth" (Hodges et al. 2009), which might affect the palatability and thus the hedonic impact of dry food rewards. Of note, when using a liquid reward no peripheral effect of SCOP has been found in FR5 and DNMTP paradigms (Hodges et al. 2009). Nevertheless, a decrease in "liking" dry food rewards after systemic administration of SCOP could interfere with behavioral performance. Particularly the m3 (Dai et al. 1991; Shida et al. 1993) but also the $\mathrm{ml}$ and $\mathrm{m} 5$ receptors have been implicated in rat salivary responses (Flynn et al. 1997; Shannon et al. 1994; Tobin et al. 2002). Thus, according to the literature BIP is capable of interfering with salivation to some extent. However, the current data suggest that any reductions in salivation after BIP doses of $10 \mathrm{mg} / \mathrm{kg}$ and lower are not sufficient to interfere with food motivation. These findings are in contrast with those of SCOP, which is likely to more fully block muscarinic receptor subtypes in rat salivary glands and to profoundly affect food motivation. A central effect of SCOP might also interfere with 
incentive-driven behaviors (such as PR performance). Centrally infused SCOP in rat nucleus accumbens has been found to reduce sucrose consumption ( 1 or $10 \mu \mathrm{g} / \mathrm{side}$ ) and breakpoint $(5.0 \mu \mathrm{g} / \mathrm{side})$ in a PR paradigm (Pratt and Kelley 2004). Furthermore, muscarinic receptors appear to be implicated in reward-driven motivational behaviors via excitatory interactions with dopamine in the nucleus accumbens and ventral tegmental area (Forster et al. 2001; Yeomans and Baptista 1997).

\section{Attention}

SCOP affected performance in the attention task at all stimulus conditions (see Figs. 3, 4). At a dose of $0.3 \mathrm{mg} / \mathrm{kg}$, SCOP decreased percentage correct, increased percentage omissions and response time independent of the duration of the stimulus. Discriminability (SI) was also reduced after the $0.3 \mathrm{mg} / \mathrm{kg}$ dose; however, the effect of SCOP was dependent on stimulus duration. Response bias (index $Y$ ) was unaffected after SCOP or BIP (3 and $10 \mathrm{mg} / \mathrm{kg}$ ). BIP also did not affect any of the other measures in the attention task. In attentional paradigms such as the five-choice serial reaction time task, SCOP has been reported to disrupt visuospatial sustained attention at doses of $0.02 \mathrm{mg} / \mathrm{kg}$ and higher (Callahan et al. 1993; Cheal 1981; Hodges et al. 2009; Hoff et al. 2007; Humby et al. 1999; Leblond et al. 2002; Spinelli et al. 2006); however, behavioral effects of SCOP on attentional accuracy are not reported consistently (Andrews et al. 1992; Doty et al. 2003; Leaton and Kreindler 1972). Moreover, SCOP has been shown to influence general noncognitive performance measures, such as response latency and number of missed trials (Andrews et al. 1992; Bushnell et al. 1997; Drinkenburg et al. 1995). As SCOP also disrupted performance in the FR5 and PR10 tasks, its effect on attention could (partially) be caused by deficits in sensorimotor responding and/or food motivation. Moreover, it is unlikely that $\mathrm{m} 1$ receptor blockade underlies the attentional impairment, as BIP had no effect on this task. To the best of our knowledge, effects of $\mathrm{m} 1$ antagonists have not been assessed in attentional paradigms before. Further studies are required in order to provide more support for the lack of a role of $\mathrm{m} 1$ and potentially other muscarinic receptors in attention.

\section{Short-term memory}

Similar to its effects on the attention task, SCOP impaired various performance measures in the DNMTP task (see Figs. 5, 6). SCOP decreased percentage correct and discriminability (SI) in a delay-dependent manner, and increased response bias (index $Y$ ) delay-independently at a dose of $0.3 \mathrm{mg} / \mathrm{kg}$. SCOP already affected DNMTP performance at the shortest delay(s), whereas it failed to disrupt performance in trials with the longest delay. The latter is likely due to a floor effect; i.e., accuracy of the animals in the 16-s delay trials was already at around chance level $(50 \%$ correct) even in the vehicle condition, and therefore further impairment due to cholinergic blockade could not be induced. The different delay intervals between sample and choice phase are presumed to produce a temporal performance gradient with longer retention intervals yielding poorer DNMTP performance as short-term memory functions are taxed in an increasing manner. Thus, the disruption of DNMTP performance at the zero delay indicates an effect of SCOP on other (non)cognitive processes rather than just short-term memory. As the current study demonstrates, the effects of SCOP $(0.3 \mathrm{mg} / \mathrm{kg})$ on sensorimotor responding, food motivation and/or attention could (at least partially) underlie deficits in DNMTP performance.

The majority of studies using delayed (non)matching procedures have reported a delay-independent impairment after relatively low doses (e.g., $0.05,0.075$, and $0.1 \mathrm{mg} / \mathrm{kg}$ IP, Herremans et al. 1995; $0.1 \mathrm{mg} / \mathrm{kg}$ IP, Hodges et al. 2009), which again suggests that SCOP does not specifically affect short-term memory functions - although some articles have challenged this finding (Estape and Steckler 2002; Ruotsalainen et al. 1998; Santi and Weise 1995; Stanhope et al. 1995). Furthermore, in most studies using systemic injections SCOP also affected measures of responding; it increased number of omissions, decreased number of completed trials and increased response latency (Estape and Steckler 2002; Kirkby et al. 1995). Central administration of SCOP in the medial prefrontal cortex (Dunnett et al. 1990; Herremans et al. 1997; Herremans et al. 1996), prelimbic cortex (Granon and Poucet 1995), and hippocampus (Robinson and Mao 1997) has been shown to yield a delay-independent reduction of DNMTP response accuracy (but see Broersen et al. 1994; Broersen et al. 1995; Dunnett et al. 1990; Granon et al. 1995) and increases in number of omissions (Robinson and Mao 1997).

It is likely that DNMTP deficits produced by SCOP can be partially attributed to $\mathrm{m} 1$ blockade, which is in line with the results reported by Bymaster et al. (1993). BIP (3 mg/ $\mathrm{kg}$ ) was found to decrease percentage correct and discriminability (SI) in a delay-dependent manner, and increase response bias (index $Y$ ) delay-independently. BIP did not influence response time at the doses used in the DNMTP (1 and $3 \mathrm{mg} / \mathrm{kg}$, IP) which is in line with our findings in the FR5 task. As is shown in Figs. 5 and 6, BIP did not affect DNMTP performance at the zero delay. However, as the delay interval increased, BIP increasingly impaired accuracy performance as compared with the vehicle condition. Thus, the disruption of DNMTP performance at longer delays but not the shortest delay indicates a genuine effect of BIP on short-term memory functions rather than other 
(non)cognitive processes. These effects are unlikely to be caused by deficits in sensorimotor responding, food motivation or attention, as BIP (at a dose of $3 \mathrm{mg} / \mathrm{kg}$ ) did not affect performance on the FR5 or PR10 schedule of reinforcement or in the attention task. Of note, the lack of an effect of BIP at the 16-s delay is again likely due to a floor effect. Taken together, these findings suggest a role for the $\mathrm{m} 1$ receptor in mediating short-term memory functions. This would implicate selective $\mathrm{ml}$ antagonists such as BIP as a promising alternative instead of the gold standard drug SCOP as a tool for inducing cholinergic mnemonic impairments in animals.

Effects of systemic administration of BIP on DNMTP performance have not been assessed previously; however, $\mathrm{ml}$ antagonists have been found to affect performance in a variety of other behavioral tasks which measure (shortterm) memory. For instance, after systemic injections deficits have been reported in passive avoidance tasks (Fornari et al. 2000; Kimura et al. 1999; Kramer-Soares et al. 2006; Roldán et al. 1997), contextual fear conditioning (Kramer-Soares et al. 2006; but see Sheffler et al. 2009), spatial alternation (Bymaster et al. 1993), and object recognition (Myhrer et al. 2004; 2008). Furthermore, m1 agonists have been shown to improve DNMTP performance in animals which were cognitively impaired after cholinergic lesioning (McDonald et al. 1998), SCOP administration or aging (Bartholomeo et al. 2000), which suggests that enhanced $\mathrm{ml}$ signaling can be sufficient in order to reverse memory deficits. Infusion of the muscarinic $\mathrm{m} 1$ antagonist pirenzepine ( $35 \mu \mathrm{g}$ in $0.5 \mu \mathrm{L} /$ side) in the dorsal hippocampus impaired accuracy performance on a DNMTP task (Messer et al. 1990; Messer et al. 1987); this implicates the importance of $\mathrm{m} 1$ receptor signaling in the hippocampus for accurate DNMTP responding.

Of note, there are some indications that the $\mathrm{m} 1$ receptor might also be involved in reversal learning ( $\mathrm{McCool}$ et al. 2008; Tzavos et al. 2004) and anxiety (Wall et al. 2001). In addition, muscarinic $(\mathrm{m} 1)$ blockade in nonhippocampal brain regions might also be responsible for short-term memory effects; for instance, intact performance on nonmatching tasks seems to also require the prefrontal, entorhinal, and perirhinal cortices (Otto and Eichenbaum 1992) Thus, our study does not exclude the involvement of muscarinic receptor subtypes other than $\mathrm{m} 1$ and brain regions other than the septo-hippocampal system in memory functions, nor the engagement of the $\mathrm{m} 1$ receptor in other cognitive processes besides memory (see for instance Araya et al. 2006; Carey et al. 2001; Daniel and Dohanich 2001; McCool et al. 2008; Messer and Miller 1988; Poulin et al. 2010; Power et al. 2003; Quirion et al. 1995; Tzavos et al. 2004; Wall et al. 2001; Wess 2004).

In fact, the manner in which $\mathrm{m} 1$ receptors affect memory processes is still under investigation; one possibility is the modulation of glutamatergic neurotransmission and/or synaptic plasticity (see Caulfield 1993; Hasselmo 1999; 2006). Muscarinic $\mathrm{m} 1$ receptors couple to Gq-proteins which activate several signaling cascades via phospholipase (PL)C (Caulfield 1993; Jones 1993; Liu et al. 2006), which can ultimately influence $\mathrm{Ca}^{2+}$ and $\mathrm{K}^{+}$currents (Liu et al. 2006), raise cyclic AMP levels (Jones 1993), and can stimulate other receptor systems such as glutamatergic $N$ methyl-D-aspartate (NMDA) receptor currents produced by hippocampal CA1 pyramidal neurons (Calabresi et al. 1998; Ma et al. 2009; Marino et al. 1998). Moreover, m1 receptors and NR1a NMDA receptor subunits were found to be colocalized at glutamatergic synapses, suggestive of a direct interaction between the two receptor systems. A link between $\mathrm{m} 1$ receptor signaling and long-term potentiation (LTP), a mechanism which is thought to underlie learning and memory processes, has also been put forward (Boddeke et al. 1992; Burgard and Sarvey 1990; Calabresi et al. 1999; Doralp and Leung 2008; Kamsler et al. 2010; Ovsepian et al. 2004; Shinoe et al. 2005). For instance, it has been shown that muscarinic agonists and antagonists which act preferentially on the $\mathrm{m} 1$ receptor are able to facilitate or prevent the induction of LTP in rat dentate gyrus (Burgard and Sarvey 1990), CA1 (Boddeke et al. 1992; Doralp and Leung 2008; Ovsepian et al. 2004), and striatum (Calabresi et al. 1999), respectively.

Future studies on the role of muscarinic receptors should focus on determining whether there exists some degree of dissociation between muscarinic receptor subtypes in terms of their involvement in memory (or other cognitive functions) as is reflected by their differential distribution in the brain (e.g., Rouse and Levey 1996). It is likely that particular muscarinic subtypes are only important for a restricted (set of) cognitive subdomain(s); e.g., hippocampal $\mathrm{m} 1$ receptors are important for working but not reference memory (Ohno et al. 1994). Furthermore, it is imperative that the manner in which $\mathrm{m} 1$ receptors influence memory processes is more extensively investigated. Information on the exact signaling cascade(s) downstream of the muscarinic $\mathrm{m} 1$ receptor that are responsible for its effects on memory could lead to interesting implications for the development of novel treatments for disorders in which memory is impaired, such as Alzheimer's disease or schizophrenia. Lastly, additonal behavioral validation is required to firmly establish the usability of $\mathrm{m} 1$ antagonists instead of the gold standard SCOP for producing cholinergic amnesia in healthy animals and human participants.

Acknowledgments We would like to thank Nick Broers for his valuable statistical advice. These experiments complied with the current Dutch governmental guidelines on animal research. The authors declare that, except for income received from their primary employer, no financial support or compensation has been received from any individual or corporate entity over the past 3 years for 
research or professional service. There are no personal financial holdings that could be perceived as constituting a potential conflict of interest.

Open Access This article is distributed under the terms of the Creative Commons Attribution Noncommercial License which permits any noncommercial use, distribution, and reproduction in any medium, provided the original author(s) and source are credited.

\section{References}

Andrews JS, Grützner M, Stephens DN (1992) Effects of cholinergic and non-cholinergic drugs on visual discrimination and delayed visual discrimination performance in rats. Psychopharmacology 106:523-530

Andrews JS, Jansen JHM, Linders S, Princen A (1994) Effects of disrupting the cholinergic system on short-term spatial memory in rats. Psychopharmacology 115:485-494

Araya R, Noguchi T, Yuhki M, Kitamura N, Higuchi M, Saido TC, Seki K, Itohara S, Kawano M, Tanemura K, Takashima A, Yamada K, Kondoh Y, Kanno I, Wess J, Yamada M (2006) Loss of M5 muscarinic acetylcholine receptors leads to cerebrovascular and neuronal abnormalities and cognitive deficits in mice. Neurobiol Dis 24:334-344

Aura J, Sirviö J, Riekkinen P (1997) Methoctramine moderately improves memory but pirenzepine disrupts performance in delayed non-matching to position test. Eur J Pharmacol 333: 129-134

Barak S, Weiner I (2009) Towards an animal model of an antipsychotic drug-resistant cognitive impairment in schizophrenia: scopolamine induces abnormally persistent latent inhibition, which can be reversed by cognitive enhancers but not by antipsychotic drugs. Int J Neuropsychopharmacol 12:227-241

Bartholomeo AC, Morris H, Buccafusco JJ, Kille N, RosenzweigLipson S, Husbands MG, Sabb AL, Abou-Gharbia M, Moyer JA, Boast CA (2000) The preclinical pharmacological profile of WAY-132983, a potent M1 preferring agonist. J Pharmacol Exp Ther 292:584-596

Bartus RT, Dean RL, Beer B, Lippa AS (1982) The cholinergic hypothesis of geriatric memory dysfunction. Science 217:408 417

Blokland A (1995) Acetylcholine: a neurotransmitter for learning and memory? Brain Res Rev 21:285-300

Blokland A, Șik A, Van Der Staay FJ (2004) Delayed non-matching to position performance in aged hybrid Fischer $344 \times$ Brown Norway rats: a longitudinal study. Brain Res Bull 64:39-46

Boddeke EWGM, Enz A, Shapiro G (1992) SDZ ENS 163, a selective muscarinic $M_{1}$ receptor agonist, facilitates the induction of longterm potentiation in rat hippocampal slices. Eur $\mathrm{J}$ Pharmacol 222:21-25

Bolden C, Cusack B, Richelson E (1992) Antagonism by antimuscarinic and neuroleptic compounds at the five cloned human muscarinic cholinergic receptors expressed in Chinese hamster ovary cells. J Pharmacol Exp Ther 260:576-580

Broersen LM, Heinsbroek RPW, de Bruin JPC, Joosten RNJ, van Hest A, Olivier B (1994) Effects of local application of dopaminergic drugs into the dorsal part of the medial prefrontal cortex of rats in a delayed matching to position task: comparison with local cholinergic blockade. Brain Res 645:113-122

Broersen LM, Heinsbroek RPW, de Bruin JPC, Uylings HBM, Olivier B (1995) The role of the medial prefrontal cortex of rats in shortterm memory functioning: further support for involvement of cholinergic, rather than dopaminergic mechanisms. Brain Res 674:221-229
Buccafusco JJ, Terry AV, Webster SJ, Martin D, Hohnadel EJ, Bouchard KA, Warner SE (2008) The scopolamine-reversal paradigm in rats and monkeys: the importance of computerassisted operant-conditioning memory tasks for screening drug candidates. Psychopharmacology 199:481-494

Burgard EC, Sarvey JM (1990) Muscarinic receptor activation facilitates the induction of long-term potentiation (LTP) in the rat dentate gyrus. Neurosci Lett 116:34-39

Bushnell PJ, Oshiro WM, Padnos BK (1997) Detection of visual signals by rats: effects of chlordiazepoxide and cholinergic and adrenergic drugs on sustained attention. Psychopharmacology $134: 230-241$

Bymaster FP, Heath I, Hendrix JC, Shannon HE (1993) Comparative behavioral and neurochemical activities of cholinergic antagonists in rats. J Pharmacol Exp Ther 267:16-24

Bymaster FP, McKinzie DL, Felder CC, Wess J (2003) Use of M1-M5 muscarinic receptor knockout mice as novel tools to delineate the physiological roles of the muscarinic cholinergic system. Neurochem Res 28:437-442

Calabresi P, Centonze D, Gubellini P, Pisani A, Bernardi G (1998) Endogenous ACh enhances striatal NMDA-responses via M1like muscarinic receptors and PKC activation. Eur J Neurosci 10:2887-2895

Calabresi P, Centonze D, Gubbellini P, Bernardi G (1999) Activation of M1-like muscarinic receptors is required for the induction of corticostriatal LTP. Neuropharmacology 38:323-326

Callahan MJ, Kinsora JJ, Harbaugh RE, Reeder TM, Davis RE (1993) Continuous icv infusion of scopolamine impairs sustained attention of rhesus monkeys. Neurobiol Aging $14: 147-151$

Carey GJ, Billard W, Binch H, Cohen-Williams M, Crosby G, Grzelak M, Guzik H, Kozlowksi JA, Lowe DB, Pond AJ, Tedesco RP, Watkins RW, Coffin VL (2001) SCH 57790, a selective muscarinic M2 receptor antagonist, releases acetylcholine and produces cognitive enhancement in laboratory animals. Eur J Pharmacol 431:189-200

Caulfield MP (1993) Muscarinic receptors - characterization, coupling and function. Pharmacol Ther 58:319-379

Caulfield MP, Birdsall NJM (1998) International union of pharmacology: XVII. Classification of muscarinic acetylcholine receptors. Pharmacol Rev 50:279-290

Cheal ML (1981) Scopolamine disrupts maintenance of attention rather than memory processes. Behav Neural Biol 33:163-187

Conn PJ, Jones CK, Lindsley CW (2009) Subtype-selective allosteric modulators of muscarinic receptors for the treatment of CNS disorders. Cell 30:148-155

Cunha GMA, Canas PM, Melo CS, Hockemeyer J, Müller CE (2008) Adenosine A2A receptor blockade prevents memory dysfunction caused by $\beta$-amyloid peptides but not by scopolamine or MK801. Exp Neur 210:776-781

Dai Y, Ambudkar IS, Horn VJ, Yeh C, Kousvelari EE, Wall SJ, Li M, Yasuda RP, Wolfe BB, Baum BJ (1991) Evidence that M3 muscarinic receptors in rat parotid gland couple to two second messenger systems. Am J Physiol 261:C1063-C1073

Daniel JM, Dohanich GP (2001) Acetylcholine mediates the estrogeninduced increase in NMDA receptor binding in CA1 of the hippocampus and the associated improvement in working memory. J Neurosci 21:6949-6956

De Klippel N, Sarre S, Ebinger G, Michotte Y (1993) Effect of M1- and M2-muscarinic drugs on striatal dopamine release and metabolism: an in vivo microdialysis study comparing normal and 6-hydroxydopamine-lesioned rats. Brain Res 630:57-64

Doralp S, Leung LS (2008) Cholinergic modulation of hippocampal CA1 basal-dendritic long-term potentiation. Neurobiol Learn Mem 90:382-388 
Doty RL, Bagla R, Misra R, Mueller E, Kerr K (2003) No influence of scopolamine hydrobromide on odor detection performance of rats. Chem Senses 28:761-765

Drinkenburg WHIM, Sondag HNPM, Coenders CJH, Andrews JS, Vossen JMH (1995) Effects of selective antagonism or depletion of the cholinergic system on visual discrimination performance in rats. Behav Pharmacol 6:695-702

Dunnett SB, Wareham AT, Torres EM (1990) Cholinergic blockade in prefrontal cortex and hippocampus disrupts short-term memory in rats. NeuroReport 1:61-64

Estape N, Steckler T (2002) Cholinergic blockade impairs performance in operant DNMTP in two inbred strains of mice. Pharmacol Biochem Behav 72:319-334

Evans HL (1975) Scopolamine effects on visual discrimination: modifications related to stimulus control. J Pharmacol Exp Ther 195:105-113

Everitt BJ, Robbins TW (1997) Central cholinergic systems and cognition. Annu Rev Psychol 48:649-684

Fibiger HC (1991) Cholinergic mechanisms in learning, memory and dementia: a review of recent evidence. Trends Neurosci 14:220 223

Flynn DD, Reever CM, Ferrari-DiLeo G (1997) Pharmacological strategies to selectively label and localize muscarinic receptor subtypes. Drug Dev Res 40:104-116

Fornari RV, Moreira KM, Oliviera MGM (2000) Effects of the selective M1 muscarinic receptor antagonist dicyclomine on emotional memory. Learn Mem 7:287-292

Forster GL, Yeomans JS, Takeuchi J, Blaha CD (2001) M5 muscarinic receptors are required for prolonged accumbal dopamine release after electrical stimulation of the pons in mice. J Neurosci 21:1-6

Frey KA, Ehrenkaufer RL, Agranoff BW (1985) Quantitative in vivo receptor binding. II. Autoradiographic imaging of muscarinic cholinergic receptors. J Neurosci 5:2407-2414

Gerber DJ, Sotnikova TD, Gainetdinov RR, Huang SY, Caron MG, Tonegawa S (2001) Hyperactivity, elevated dopaminergic transmission and response to amphetamine in M1 muscarinic acetylcholine receptor-deficient mice. P Natl Acad Sci 98:15312-15317

Granon S, Poucet B (1995) Medial prefrontal lesions in the rat and spatial navigation: evidence for impaired planning. Behav Neurosci 109:474-484

Granon S, Poucet B, Thinus-Blanc C, Changeux J-P, Vidal C (1995) Nicotinic and muscarinic receptors in the rat prefrontal cortex: differential roles in working memory, response selection and effortful processing. Psychopharmacology 119:139-144

Harvey JA, Gormezano I, Cool-Hauser VA (1983) Effects of scopolamine and methylscopolamine on classical conditioning of the rabbit nictitating membrane response. J Pharmacol Exp Ther 225:42-49

Hasselmo ME (1999) Neuromodulation: acetylcholine and memory consolidation. Trends Cogn Sci 3:351-359

Hasselmo ME (2006) The role of acetylcholine in learning and memory. Curr Opin Neurobiol 16:710-715

Herremans AH, Hijzen TH (1997) The delayed-conditionaldiscrimination task improves measurement of working memory in rats. Neurosci Biobehav Rev 21:371-379

Herremans AHJ, Hijzen TH, Olivier B, Slangen JL (1995) Cholinergic drug effects on a delayed conditional discrimination task in the rat. Behav Neurosci 109:426-435

Herremans AHJ, Hijzen TH, Welborn PFE, Olivier B, Slangen JL (1996) Effects of infusion of cholinergic drugs into the prefrontal cortex area on delayed matching to position performance in the rat. Brain Res 711:102-111

Herremans AHJ, Hijzen TH, Olivier B (1997) Effects of cholinergic drug infusions into the dorsal part of the medial prefrontal cortex on delayed conditional discrimination peformance in the rat. Behav Brain Res 84:291-299

Hodges DB Jr, Lindner MD, Hogan JB, Jones KM, Markus EJ (2009) Scopolamine induced deficits in a battery of rat cognitive tests: Comparisons of sensitivity and specificity. Behav Pharmacol 20:237-251

Hodos W (1961) Progressive ratio as a measure of reward strength. Science 134:943-944

Hoff EI, van Oostenbrugge RJ, Liedenbaum M, Steinbusch HW, Blokland A (2007) Effects of right-hemisphere cortical infarction and muscarinic acetylcholine receptor blockade on spatial visual attention performance in rats. Behav Brain Res 178:62-69

Humby T, Laird FM, Davies W, Wilkinson LS (1999) Visuospatial attentional functioning in mice: interactions between cholinergic manipulations and genotype. Eur J Neurosci 11:2813-2823

Jones SVP (1993) Muscarinic receptor subtypes: modulation of ion channels. Life Sci 52:457-464

Jones CK, Shannon HE (2000) Muscarinic cholinergic modulation of prepulse inhibition of the acoustic startle reflex. J Pharmacol Exp Ther 294:1017-1023

Kamsler A, McHugh TJ, Gerber D, Huang SY, Tonegawa S (2010) Presynaptic $\mathrm{m} 1$ muscarinic receptors are necessary for mGluR long-term depression in the hippocampus. Proc Natl Acad Sci USA 107:1618-1623

Katayama S, Ishizaki F, Yamamura Y, Khoriyama T, Kito S (1990) Effects of anticholinergic antiparkinsonian drugs on binding of muscarinic receptor subtypes in rat brain. Res Commun Chem Pathol 69:261-270

Kimura Y, Ohue M, Kitaura T, Kihira K (1999) Amnesic effects of the anticholinergic drugs, trihexyphenidyl and biperiden: differences in binding properties to the brain muscarinic receptor. Brain Res 834:6-12

Kirkby DL, Jones DNC, Higgins GA (1995) Influence of prefeeding and scopolamine upon performance in a delayed matching-toposition task. Behav Brain Res 67:221-227

Klinkenberg I, Blokland A (2010) The validity of scopolamine as a pharmacological model for cognitive impairment: a review of animal behavioral studies. Neurosci Biobehav Rev 34:13071350

Kramer-Soares JC, Vecchio-Fornari R, Menezes-Oliviera MG (2006) Role of muscarinic $\mathrm{M}_{1}$ receptors in inhibitory avoidance and contextual fear conditioning. Neurobiol Learn Mem 86:188-196

Leaton RN, Kreindler M (1972) Effects of physostigmine and scopolamine on operant brightness discrimination in the rat. Physiol Behav 9:121-123

Leblond L, Beaufort C, Delerue F, Durkin T (2002) Differential roles for nicotinic and muscarinic cholinergic receptors in sustained visuo-spatial attention? A study using a 5-arm maze protocol in mice. Behav Brain Res 128:91-102

Liu W (1996) Effects of antimuscarinic antiparkinsonian drugs on brightness discrimination performance in rats. Pharmacol Biochem Behav 54:425-430

Liu L, Zhao R, Bai Y, Stanish LF, Evans JE, Sanderson MJ, Bonventre JV, Rittenhouse AR (2006) M1 muscarinic receptors inhibit L-type $\mathrm{Ca}^{2+}$ current and M-current by divergent signal transduction cascades. J Neurosci 26:11588-11598

Loiseau F, Dekeyne A, Millan MJ (2008) Pro-cognitive effects of 5HT6 receptor antagonists in the social recognition procedure in rats: implication of the frontal cortex. Psychopharmacology 196:93-104

Ma L, Seager MA, Wittmann M, Jacobson M, Bickel D, Burno M, Jones K, Kuzmick-Graufelds V, Xu G, Pearson M, McCampbell A, Gaspar R, Shugrue P, Danziger A, Regan C, Flick R, Pascarella D, Garson S, Doran S, Kreatsoulas C, Veng L, Lindsey CW, Shipe W, Kuduk S, Sur C, Kinney G, Seabrook GR, Ray WJ (2009) Selective activation of the $M_{1}$ muscarinic 
acetylcholine receptor achieved by allosteric potentiation. P Natl Acad Sci 106:15950-15955

Marino MJ, Rouse ST, Levey AI, Potter LT, Conn PJ (1998) Activation of the genetically defined $\mathrm{ml}$ muscarinic receptor potentiates $\mathrm{N}$-methyl-D-aspartate (NMDA) receptor currents in hippocampal pyramidal cells. Proc Natl Acad Sci USA 95:11465-11470

McCool MF, Patel S, Talati R, Ragozzino ME (2008) Differential involvement of M1-type and M4-type muscarinic cholinergic receptors in the dorsomedial striatum in task switching. Neurobiol Learn Mem 89:114-124

McDonald MP, Willard LB, Wenk GL, Crawly JN (1998) Coadministration of galanin antagonist M40 with a muscarinic M1 agonist improves delayed nonmatching to position choice accuracy in rats with cholinergic lesions. J Neurosci 18:5078-5085

Messer WS, Miller MD (1988) Intrahippocampal injections of gallamine impair learning of a memory task. Neurosci Lett 89:367-372

Messer WS, Thomas GJ, Hoss W (1987) Selectivity of pirenzepine in the central nervous system. II differential effects of pirenzepine and scopolamine on performance of a representational memory task. Brain Res 407:37-45

Messer WS, Bohnett M, Stibbe J (1990) Evidence for a preferential involvement of $\mathrm{M}_{1}$ muscarinic receptors in representational memory. Neurosci Lett 116:184-189

Mirza NR, Stolerman IP (2000) The role of nicotinic and muscarinic acetylcholine receptors in attention. Psychopharmacology 148:243-250

Moore H, Dudchenko P, Comer KS, Bruno JP, Sarter M (1992) Central versus peripheral effects of muscarinic antagonists: the limitations of quarternary ammonium derivatives. Psychopharmacology 108:241-243

Myers TM, Galbicka G, Sipos ML, Varadi S, Oubre JL, Clark MG (2002) Effects of anticholinergics on serial-probe recognition accuracy of rhesus macaques (Macaca mulatta). Pharmacol Biochem Behav 73:829-834

Myhrer T, Enger S, Aas P (2004) Cognitive side effects in rats caused by pharmacological agents used to prevent soman-induced lethality. Eur J Pharmacol 483:271-279

Myhrer T, Enger S, Aas P (2008) Antiparkinson drugs used as prophylactics for nerve agents: studies of cognitive side effects in rats. Pharmacol Biochem Behav 89:633-638

Nakashima E, Ishizaki F, Takeda M, Matsusushita R, Yokogawa K, Ichimura F (1993) Pharmacokinetics of anticholinergic drugs and brain muscarinic receptor alterations in streptozotocin diabetic rats. Biopharm Drug Dispos 14:673-684

Ohno M, Yamamoto T, Watanabe S (1994) Blockade of hippocampal M1 muscarinic receptors impairs working memory performance of rats. Brain Res 650:260-266

Otto T, Eichenbaum H (1992) Complementary roles of orbital prefrontal cortex and the perirhinal-entorhinal cortices in an odor-guided delayed non-matchong to sample task. Behav Neurosci 106:763-776

Ovsepian SV, Anwyl R, Rowan MJ (2004) Endogenous acetylcholine lowers the threshold for long-term potentiation induction in the CA1 area through muscarinic receptor activation: in vivo study. Eur J Neurosci 20:1267-1275

Pakarinen ED, Moerschbaecher JM (1993) Comparison of the effects of scopolamine and methylscopolamine on the performance of a fixed-ratio discrimination in squirrel monkeys. Pharmacol Biochem Behav 44:815-819

Phillips JM, McAlonan K, Robb WG, Brown VJ (2000) Cholinergic neurotransmission influences covert orientation of visuospatial attention in the rat. Psychopharmacology 150:112-116

Poulin B, Butcher A, McWilliams P, Bourgognon JM, Pawlak R, Kong KC, Bottrill A, Mistry S, Wess J, Rosethorne EM, Charlton
SJ, Tobin AB (2010) The M3-muscarinic receptor regulates learning and memory in a receptor phosphorylation/arrestindependent manner. Proc Natl Acad Sci USA 107:9440-9445

Power AE, McIntyre CK, Litmanovich A, McGaugh JL (2003) Cholinergic modulation of memory in the basolateral amygdala involves activation of both $\mathrm{m} 1$ and $\mathrm{m} 2$ receptors. Behav Pharmacol 14:207-213

Pradhan SN, Roth T (1968) Comparative behavioral effects of several anti-cholinergic agents in rats. Psychopharmacologia 12:358-366

Pratt WE, Kelley AE (2004) Nucleus accumbens acetylcholine regulates appetitive learning and motivation for food via activation of muscarinic receptors. Behav Neurosci 118:730 739

Prickaerts J, Fahrig T, Blokland A (1999) Cognitive performance and biochemical markers in septum, hippocampus and striatum of rats after an i.c.v. injection of streptozotocin: a correlation analysis. Behav Brain Res 102:73-88

Quirion R, Wilson A, Rowe W, Aubert I, Richard J, Doods H, White N, Meaney MJ (1995) Facilitation of acetylcholine release and cognitive performance by an M2-muscarinic receptor antagonist in aged memory-impaired rats. J Neurosci 15:1455-1462

Robinson JK, Mao JB (1997) Differential effects on delayed nonmatching-to-position in rats of microinjections of muscarinic receptor antagonist scopolamine or NMDA receptor antagonist MK-801 into the dorsal or ventral extent of the hippocampus. Brain Res 765:51-60

Roldán G, Bolaňos-Badillo E, González-Sánchez H, Quirarte GL, Prado-Alcalá RA (1997) Selective M1 muscarinic receptor antagonists disrupt memory consolidation of inhibitory avoidance in rats. Neurosci Lett 230:93-96

Rouse ST, Levey AI (1996) Expression of m1-m4 muscarinic acetylcholine receptor immunoreactivity in septohippocampal neurons and other identified hippocampal afferents. J Comp Neurol 375:406-416

Ruotsalainen S, Miettinen R, Macdonald E, Riekkinen M, Sirviö J (1998) The role of the dorsal raphe-serotonergic system and cholinergic receptors in the modulation of working memory. Neurosci Biobehav Rev 22:21-31

Santi A, Weise L (1995) The effects of scopolamine on memory for time in rats and pigeons. Pharmacol Biochem Behav 51:271-277

Sarter M, Bruno JP (1997) Cognitive functions of cortical acetylcholine: toward a unifying hypothesis. Brain Res Rev 23:28-46

Shannon HE, Bymaster FP, Calligaro DO, Greenwood B, Mitch CH, Sawyer BD, Ward JS, Wong DT, Olesen PH, Sheardown MJ, Swedberg MDB, Suzdak PD, Sauerberg P (1994) Xanomeline: a novel muscarinic receptor agonist with functional selectivity for M1 receptors. J Pharmacol Exp Ther 269:271-281

Sheffler DJ, Williams R, Bridges TM, Xiang Z, Kane AS, Byun NE, Jadhav S, Mock MM, Zheng F, Lewis LM, Jones CK, Niswender CM, Weaver CD, Lindsley CW, Conn PJ (2009) A novel selective muscarinic acetylcholine receptor subtype 1 antagonist reduces seizures without impairing hippocampus-dependent learning. Mol Pharmacol 76:356-368

Shida T, Tokunaga A, Kondo E, Ueda Y, Ohno K, Saika T, Kiyama H, Tohyama M (1993) Expression of muscarinic and nicotinic receptor mRNA in the salivary gland of rats: a study by in situ hybridization histochemistry. Mol Brain Res 17:335-339

Shinoe T, Matsui M, Taketo MM, Manabe T (2005) Modulation of synaptic plasticity by physiological activation of M1 muscarinic acetylcholine receptors in the mouse hippocampus. J Neurosci 25:11194-11200

Shiraishi K, Takayanagi I (1993) Subtype of muscarinic receptors mediating relaxation and contraction in the rat iris dilator smooth muscle. Gen Pharmacol 24:139-142 
Sipos ML, Burchnell V, Galbicka G (1999) Dose-response curves and time-course effects of selected anticholinergics on locomotor activity in rats. Psychopharmacology 147:250-256

Sipos ML, Burchnell V, Galbicka G (2001) Effects of selected anticholinergics on acoustic startle response in rats. J Appl Toxicol 21:S95-S101

Spinelli S, Ballard T, Feldon J, Higgins GA, Pryce CR (2006) Enhancing effects of nicotine and impairing effects of scopolamine on distinct aspects of performance in computerized attention and working memory tasks in marmoset monkeys. Neuropharmacology 51:238-250

Stanhope KJ, McLenachan AP, Dourish CT (1995) Dissociation between cognitive and motor/motivational deficits in the delayed matching to position test: effects of scopolamine, 8$\mathrm{OH}-\mathrm{DPAT}$ and EAA antagonists. Psychopharmacology 122:268-280

Steckler T (2001) Using signal detection methods for analysis of operant performance in mice. Behav Brain Res 125:237248

Syvälahti EKG, Kunelios R, Laurén L (1988) Effects of antiparkinsonian drugs on muscarinic receptor binding in rat brain, heart and lung. Basic Clin Pharmacol Toxicol 62:90-94

Taffe MA, Weed MR, Gold LH (1999) Scopolamine alters rhesus monkey performance on a novel neuropsychological test battery. Cognitive Brain Res 8:203-212

Tobin G, Giglio D, Götrick B (2002) Studies of muscarinic receptor subtypes in salivary gland function in anaesthetized rats. Auton Neurosci-Basic 100:1-9

Tzavos A, Jih J, Ragozzino ME (2004) Differential effects of M1 muscarinic receptor blockade and nicotinic receptor blockade in the dorsomedial striatum on response reversal learning. Behav Brain Res 154:245-253

Vaisman N, Pelled D (2009) n-3 phosphatidylserine attenuated scopolamine-induced amnesia in middle-aged rats. Prog NeuroPsychoph 33:952-959

van Haaren F, van Hest A (1989) The effects of scopolamine and methylscopolamine on visual and auditory discriminations in male and female Wistar rats. Pharmacol Biochem Behav 32:707-710

Volpicelli LA, Levey AI (2004) Muscarinic acetylcholine receptor subtypes in cerebral cortex and hippocampus. Prog Brain Res 145:59-66

Wall PM, Flinn J, Messier C (2001) Infralimbic muscarinic M1 receptors modulate anxiety-like behaviour and spontaneous working memory in mice. Psychopharmacology 155:58-68

Wess J (2004) Muscarinic acetylcholine receptor knockout mice: novel phenotypes and clinical implications. Annu Rev Pharmacol 44:423-450

Wezenberg E, Verkes RJ, Sabbe BG, Ruigt GS, Hulstijn W (2005) Modulation of memory and visuospatial processes by biperiden and rivastigmine in elderly healthy subjects. Psychopharmacology 181:582-594

Yeomans J, Baptista M (1997) Both nicotinic and muscarinic receptors in ventral tegmental area contribute to brain-stimulation reward. Pharmacol Biochem Behav 57:915-921

Yokogawa K, Nakashima E, Ichimura F (1990) Effect of fat tissue volume on the distribution kinetics of biperiden as a function of age in rats. Drug Metab Dispos 18:258-263

Yokogawa K, Nakashima E, Ishizaki J, Hasegawa M, Kido H, Ichimura F (1992) Brain regional pharmacokinetics of biperiden in rats. Biopharm Drug Dispos 13:131-140 